\title{
Bufalin exerts antitumor effects in neuroblastoma via the induction of reactive oxygen species-mediated apoptosis by targeting the electron transport chain
}

\author{
LIJIA PAN ${ }^{1,2^{*}}$, LITONG NIE ${ }^{3,4 *}$, SHENG YAO ${ }^{4 *}$, AIWEI BI $^{5,6}$, YANG YE $^{4-6}$, \\ YEMING WU ${ }^{1,2,7}$, ZHEN TAN ${ }^{5,8}$ and ZHIXIANG WU ${ }^{1,2,5}$
}

\begin{abstract}
${ }^{1}$ Department of Pediatric Surgery, Xinhua Hospital, School of Medicine, Shanghai Jiaotong University;
${ }^{2}$ Division of Pediatric Oncology, Shanghai Institute of Pediatric Research, Shanghai 200092, P.R. China;

${ }^{3}$ Department of Experimental Radiation Oncology, The University of Texas MD Anderson Cancer Center, Houston, TX 77030, USA; ${ }^{4}$ State Key Laboratory of Drug Research and Natural Products Chemistry Department, ${ }^{5}$ State Key Laboratory of Drug Research and Division of Antitumor Pharmacology, Shanghai Institute of Materia Medica, Chinese Academy of Sciences, Shanghai 201203; ${ }^{6}$ University of Chinese Academy of Sciences, Beijing 100049; ${ }^{7}$ Department of Pediatric Surgery, Children's Hospital of Soochow University, Suzhou, Jiangsu 215003; ${ }^{8}$ Department of Pediatric Hematology Oncology, Xinhua Hospital, School of Medicine, Shanghai Jiaotong University, Shanghai 200092, P.R. China
\end{abstract}

Received May 28, 2020; Accepted September 4, 2020

DOI: $10.3892 / \mathrm{ijmm} .2020 .4745$

\begin{abstract}
The prognosis of high-risk neuroblastoma remains poor. Clinical first-line drugs for treating neuroblastoma have been developed over the previous half-century; however, progress in the identification of new drugs with high efficiency is required. Bufalin, one of the major components of extracts obtained from the venom of the Chinese toad Bufo gargarizans, which is used to treat heart failure in Asian Pacific countries, has been reported to be a potential drug against multiple types of tumor; however, the detailed mechanisms underlying
\end{abstract}

Correspondence to: Dr Zhen Tan, Department of Pediatric Hematology Oncology, Xinhua Hospital, School of Medicine, Shanghai Jiaotong University, 1665 Kongjiang Road, Shanghai 200092, P.R. China

E-mail: tanz2008@126.com

Dr Zhixiang Wu, Department of Pediatric Surgery, Xinhua Hospital, School of Medicine, Shanghai Jiaotong University, 1665 Kongjiang Road, Shanghai 200092, P.R. China

E-mail:wuzhixiang@xinhuamed.com.cn

Abbreviations: GO, Gene Ontology; DMSO, dimethyl sulfoxide; $\mathrm{IC}_{50}$, half maximal-inhibitory concentration; DCHF-DA, 2',7'-dichlorofluorescin-diacetate; OCR, oxygen consumption rate; $\Delta \Psi \mathrm{m}$, mitochondrial membrane potential; MS, mass spectrometry; ROS, reactive oxygen species; ETC, electron transport chain; NAC, $\mathrm{N}$-acetyl-L-cysteine; PCNA, proliferating cell nuclear antigen

*Contributed equally

Key words: neuroblastoma, bufalin, chemical proteomics, ETC, mitochondria its antitumor activities remain unclear, largely due to lack of knowledge regarding its targets. In the present study, bufalin was revealed to exhibit potent antitumor effects against neuroblastoma, both in vitro and in vivo, using cell proliferation, colony formation, Transwell migration and flow cytometry assays, as well as a nude mouse subcutaneous xenograft model. Moreover, a chemically modified bufalin probe was designed to identify the potential targets of bufalin in neuroblastoma via chemical proteomics. With this strategy, it was revealed that the electron transport chain (ETC) on the inner membrane of mitochondria may contain potential targets for bufalin, and that bufalin-induced mitochondrial-dependent apoptosis may be caused by disruption of the ETC. Collectively, the present study suggests that bufalin may a promising drug for chemotherapy against neuroblastoma, and provides a foundation for further studies into the antitumor mechanisms of bufalin.

\section{Introduction}

Neuroblastoma is a common extracranial solid tumor that occurs as an embryonal malignancy (1); it typically originates from undifferentiated sympathetic nervous cells in the adrenal medulla or paravertebral sympathetic ganglia $(2,3)$. Neuroblastoma accounts for $\sim 7 \%$ of all childhood malignancies, but $13 \%$ of cancer-related mortalities in children (4). In the majority of cases, surgery cannot remove the tumors entirely when they are diagnosed (5). Neoadjuvant chemotherapy therefore becomes the first choice to create an opportunity for further surgery; however, a number of patients with neuroblastoma exhibit a minimal response to current chemotherapy treatments (6). The prognosis for high-risk neuroblastoma is poor (5-year survival rate, $<35 \%$ ) and has not markedly improved over the past few decades (7). In fact, the drugs currently used in clinical settings for treating 
neuroblastoma, such as cisplatin and cyclophosphamide, were developed in the middle of the previous century, and none of them were specifically approved for pediatric patients with neuroblastoma. Therefore, novel drugs with greater efficacy are required.

Traditional Chinese medicine has been used as a resource for developing antitumor drugs (8). Bufalin, one of the major components in extracts obtained from the venom of the parotoid glands or skin epidermal gland of the Chinese toad Bufo gargarizans, is a Traditional Chinese medicine used to treat heart failure in Asian Pacific countries (9). Previous studies have reported that bufalin exerts anticancer effects in various tumors, such as lung cancer (10), hepatic carcinoma (11) and prostate cancer (12). However, due to the unknown targets of bufalin, the detailed mechanisms underlying its antitumor activity remain unclear. Li et al (13) reported that bufalin induced the death of breast cancer cells via reactive oxygen species (ROS)-mediated receptor-interacting protein (RIP)1/RIP3/poly(ADP-ribose) polymerase (PARP)-1 pathway activation. Liu et al (14) observed that bufalin-induced inhibition of tumorigenesis depended on cell cycle arrest via the $\mathrm{c}-\mathrm{Myc} / \mathrm{NF}-\kappa \mathrm{B}$ pathway. In glioma, bufalin upregulated microRNA-203 expression to inhibit cellular proliferation and retain cancer stem cell-like phenotypes (15). In lung cancer, bufalin induced cell death by disrupting DNA damage response pathways or the PI3K/Akt pathway $(16,17)$. Degradation of the $\mathrm{Na}^{+} / \mathrm{K}^{+}$-ATPase $\alpha 1$ subunit was reported to be involved in bufalin-induced inhibition of glioblastoma (18). However, to the best of our knowledge, no studies have examined the antitumor effects of bufalin in neuroblastoma, and the direct targets of bufalin remain unknown.

In the present study, the antitumor effects of bufalin in neuroblastoma were investigated in vitro and in vivo. Moreover, a bufalin probe was designed to explore the potential targets of bufalin in neuroblastoma via chemical proteomics analysis, with the results suggesting an important role of electron transport chain (ETC) disruption in bufalin-induced mitochondrial-dependent apoptosis.

\section{Materials and methods}

Cell lines and reagents. The neuroblastoma cell lines SK-N-BE(2) (MYCN amplification) and SH-SY5Y (MYCN non-amplification), and lung cancer cell lines A549 were obtained from Guangzhou Jennio Biotech Co., Ltd. Cell line authentication by STR profiling was conducted by Genewiz, Inc. All cells were cultured in a $5 \% \mathrm{CO}_{2}$ humidified incubator at $37^{\circ} \mathrm{C}$ in Dulbecco's modified Eagle's medium (DMEM; HyClone; Cytiva) containing 10\% fetal bovine serum (FBS; Gibco; Thermo Fisher Scientific, Inc.). Bufalin (MedChemExpress), N-acetyl-L-cysteine (NAC; cat. no. S0077; Beyotime Institute of Biotechnology) and the bufalin-derived probe CS-P1 were dissolved in dimethyl sulfoxide (DMSO) at a stock concentration of $100 \mathrm{mM}$ and diluted with medium before experimentation.

Synthesis of CS-P1. N,N'-dicyclohexylcarbodiimide (12 mg, $0.056 \mathrm{mmol}, 1.1 \mathrm{eq}$.$) and 4-dimethylaminopyridine (1 \mathrm{mg}$, $0.008 \mathrm{mmol}, 0.15 \mathrm{eq}$.) were added to a solution of bufalin
(20 mg, $0.052 \mathrm{mmol}$ ) and pent-4-ynoic acid (6 mg, $0.056 \mathrm{mmol}$, 1.1 eq.) in $5 \mathrm{ml}$ dry dichloromethane; the reaction mixture was stirred at room temperature overnight. The solution was diluted with $20 \mathrm{ml}$ water and extracted with dichloromethane $(5 \mathrm{ml})$ for three times. The combined organic layer was washed with water, dried with $\mathrm{MgSO}_{4}$ and then evaporated. The residue was purified via preparative thin-layer chromatography using petroleum ether:ethyl acetate (4:1) to yield CS-P1 (13 mg, 54\%). CS-P1 is a white solid with electrospray ionization-mass spectrometry (MS) $m / z 467.3[\mathrm{M}+\mathrm{H}]^{+}$. ${ }^{1} \mathrm{H}$ NMR $\left(500 \mathrm{MHz}, \mathrm{CDCl}_{3}\right) \delta 7.84(1 \mathrm{H}, \mathrm{dd}, J=2.6,9.8 \mathrm{~Hz}, \mathrm{H}-22), 7.23$ (1H, d, J=2.6 Hz, H-23), 6.27 (1H, d, J=9.8 Hz, H-21), 5.13 (2H, br.s, H-3, CH $\equiv), 0.70$ (3H, s, H-18), 0.95 (3H, s, H-19), 2.54 (1H, m, H-17), 2.00-0.85 (26H, m). ${ }^{13} \mathrm{C} \mathrm{NMR} 125 \mathrm{MHz}^{\left.-\mathrm{CDCl}_{3}\right)}$ $\delta 171.2$ (-CH2-COO-), 162.4 (C-24), 148.5 (C-21), 146.7 (C-22), 122.6 (C-20), 115.3 (C-23), 85.3 (C-14), 82.6 (三C-), 77.2 (C-3), $70.8(\mathrm{CH} \equiv), 51.2(\mathrm{C}-17), 48.4(\mathrm{C}-13), 42.4(\mathrm{C}-8), 40.8(\mathrm{C}-12), 36.8$ (C-5), 35.9 (C-9), 35.1 (C-10), 33.8 (-ㅌH2-COO), 32.8 (C-15), 30.4 (C-4), 28.7 (C-16), 26.6 (C-6), 25.6 (C-1), 24.7 (C-2), 23.7 (C-19), 21.4 (C-7), 21.3 (C-11), 16.5 (C-18), 14.3 (-ㄷH2-C $\equiv \mathrm{CH})$.

Cell proliferation and colony formation assays. Cell Counting Kit-8 reagent (Dojindo Molecular Technologies, Inc.) was used to assess cell proliferation ability. SK-N-BE(2), SH-SY5Y and A549 cells were cultured in complete medium at $37^{\circ} \mathrm{C}$ in 96 -well plates at a density of $1 \times 10^{4}$ cells/well and were treated with bufalin or CS-P1 in a dose-(1-1,000 nM) and time-dependent $(24,48$ or $72 \mathrm{~h})$ manner at $37^{\circ} \mathrm{C}$. Then, CCK- 8 reagent was added for $2 \mathrm{~h}$ incubation. The absorbance value at $450 \mathrm{~nm}$ was measured with an Automated Microplate Reader (Bio-Rad Laboratories, Inc.) to assess cell proliferation ability over 24,48 or 72 h. The half maximal-inhibitory concentration $\left(\mathrm{IC}_{50}\right)$ of each drug was calculated based on the dose-effect curve.

In the colony formation assays, $\mathrm{SK}-\mathrm{N}-\mathrm{BE}(2)$ cells were treated as follows: $0.1 \%$ DMSO for $48 \mathrm{~h}, 45 \mathrm{nM}$ bufalin for $48 \mathrm{~h}, 90 \mathrm{nM}$ bufalin for $48 \mathrm{~h}$ or $90 \mathrm{nM}$ bufalin for $72 \mathrm{~h}$. SH-SY5Y cells were treated as follows: $0.1 \%$ DMSO for $48 \mathrm{~h}$, $15 \mathrm{nM}$ bufalin for $48 \mathrm{~h}, 30 \mathrm{nM}$ bufalin for $48 \mathrm{~h}$ or $30 \mathrm{nM}$ bufalin for $72 \mathrm{~h}$. For CS-P1 experiments, SK-N-BE(2) and SH-SY5Y cells were treated with CS-P1 (329 nM) for $72 \mathrm{~h}$ at $37^{\circ} \mathrm{C}$. Then, SK-N-BE(2) and SH-SY5Y cells were seeded into complete medium at a density of $1 \times 10^{4}$ cells/well in six-well plates. After 1 week of culture, the colonies were fixed in $4 \%$ paraformaldehyde (Sigma-Aldrich; Merck KGaA) for $15 \mathrm{~min}$ at room temperature. The colonies were stained with $0.5 \%$ crystal violet (Beyotime Institute of Biotechnology) for $15 \mathrm{~min}$ at room temperature. Finally, a camera was used to acquire images, and the number of colonies was counted.

Cell migration assays. Cell migration assays were performed in 24-well Transwell chambers (Corning, Inc.). Briefly, SK-N-BE(2) cells were treated as follows: 0.1\% DMSO for $48 \mathrm{~h}, 45 \mathrm{nM}$ bufalin for $48 \mathrm{~h}, 90 \mathrm{nM}$ bufalin for $48 \mathrm{~h}$ or $90 \mathrm{nM}$ bufalin for $72 \mathrm{~h}$. SH-SY5Y cells were treated as follows: $0.1 \%$ DMSO for $48 \mathrm{~h}, 15 \mathrm{nM}$ bufalin for $48 \mathrm{~h}, 30 \mathrm{nM}$ bufalin for $48 \mathrm{~h}$ and $30 \mathrm{nM}$ bufalin for $72 \mathrm{~h}$. For CS-P1 experiments, SK-N-BE(2) and SH-SY5Y cells were treated with CS-P1 (329 nM) for $72 \mathrm{~h}$ at $37^{\circ} \mathrm{C}$. Then, SK-N-BE(2) and SH-SY5Y cells were plated into the upper chambers 
the Transwell inserts with $200 \mu 1$ serum-free DMEM at a density of $2 \times 10^{4}$ cells/well, and $500 \mu 1$ complete DMEM containing $10 \%$ FBS was added to the lower chambers. After $48 \mathrm{~h}$ of culture at $37^{\circ} \mathrm{C}, 4 \%$ paraformaldehyde was used to fix the cells at room temperature for $15 \mathrm{~min}$, and $0.5 \%$ crystal violet was used to stain the cells for $15 \mathrm{~min}$ at room temperature. Finally, images (magnifications, x100 and $\mathrm{x} 200$ ) were acquired under an optical microscope (Leica Microsystems GmbH). Five randomly selected fields containing migrated cells in each lower chamber were counted.

Analysis of intracellular ROS. SK-N-BE(2) cells were treated as follows: $0.1 \%$ DMSO for $48 \mathrm{~h}, 45 \mathrm{nM}$ bufalin for $48 \mathrm{~h}$, $90 \mathrm{nM}$ bufalin for $48 \mathrm{~h}$ or $90 \mathrm{nM}$ bufalin for $72 \mathrm{~h}$. SH-SY5Y cells were treated as follows: $0.1 \%$ DMSO for $48 \mathrm{~h}, 15 \mathrm{nM}$ bufalin for $48 \mathrm{~h}, 30 \mathrm{nM}$ bufalin for $48 \mathrm{~h}$ or $30 \mathrm{nM}$ bufalin for $72 \mathrm{~h}$. For NAC experiments, SK-N-BE(2) and SH-SY5Y cells were pretreated with NAC $(5 \mathrm{mM})$ for $2 \mathrm{~h}$ at $37^{\circ} \mathrm{C}$, then SK-N-BE(2) cells were treated with bufalin (90 nM) for $48 \mathrm{~h}$ and SH-SY5Y were treated with bufalin $(30 \mathrm{nM})$ for $48 \mathrm{~h}$. For CS-P1 experiments, SK-N-BE(2) and SH-SY5Y were treated with CS-P1 (329 nM) for $72 \mathrm{~h}$ at $37^{\circ} \mathrm{C}$. SK-N-BE(2) and SH-SY5Y cells were incubated with $2^{\prime}, 7^{\prime}$-dichlorofluorescin-diacetate (DCHF-DA; cat. no. S0033; Beyotime Institute of Biotechnology) in six-well plates at a density of $2 \times 10^{5}$ cells/well for intracellular ROS measurement. Briefly, after incubation with $10 \mu \mathrm{M}$ DCHF-DA for $30 \mathrm{~min}$ in the dark at $37^{\circ} \mathrm{C}$, the cells were harvested, washed and resuspended in serum-free DMEM. Images (magnification, x200) of five randomly selected fields were captured under a fluorescence microscope (Leica Microsystems $\mathrm{GmbH}$ ). The relative optical density (OD) was measured with ImageJ 1.4.3 software (National Institutes of Health).

Mitochondrial membrane potential $(\Delta \Psi m)$ assay. A $\Delta \Psi \mathrm{m}$ assay kit with JC-1 (cat. no. C2006; Beyotime Institute of Biotechnology) was used to determine the $\Delta \Psi \mathrm{m}$. According to the manufacturer's protocols, cells treated with CS-P1 (329 nM, $72 \mathrm{~h}$ ) at $37^{\circ} \mathrm{C}$ were incubated with $1 \mathrm{X} \mathrm{JC}-1$ for $30 \mathrm{~min}$ in the dark at $37^{\circ} \mathrm{C}$. Next, the cells were washed twice with phosphate-buffered saline (PBS) and observed with a fluorescence microscope (Leica Microsystems $\mathrm{GmbH}$ ). The relative OD was measured with ImageJ 1.4.3 software.

Apoptosis assay. SK-N-BE(2) cells were treated as follows: $0.1 \%$ DMSO for $48 \mathrm{~h}, 45 \mathrm{nM}$ bufalin for $48 \mathrm{~h}, 90 \mathrm{nM}$ bufalin for $48 \mathrm{~h}$ or $90 \mathrm{nM}$ bufalin for $72 \mathrm{~h}$. SH-SY5Y cells were treated as follows: $0.1 \%$ DMSO for $48 \mathrm{~h}, 15 \mathrm{nM}$ bufalin for $48 \mathrm{~h}$, $30 \mathrm{nM}$ bufalin for $48 \mathrm{~h}$ or $30 \mathrm{nM}$ bufalin for $72 \mathrm{~h}$. For NAC experiments, SK-N-BE(2) and SH-SY5Y cells were pretreated with NAC (5 mM) for $2 \mathrm{~h}$ at $37^{\circ} \mathrm{C}$, then SK-N-BE(2) cells were treated with bufalin (90 nM, $48 \mathrm{~h})$ and $\mathrm{SH}-\mathrm{SY} 5 \mathrm{Y}$ were treated with bufalin (30 nM, $48 \mathrm{~h}$ ). The cell apoptosis assay was performed using an Annexin V-FITC Apoptosis Detection kit (cat. no. C1062L; Beyotime Institute of Biotechnology). According to the manufacturer's protocol, $1 \times 10^{6}$ pretreated cells were washed with PBS three times after being isolated via centrifugation at $4^{\circ} \mathrm{C}$ for $3 \mathrm{~min}$ at $1,000 \mathrm{x}$. Next, $5 \mu \mathrm{l}$ Annexin V-FITC in $195 \mu \mathrm{l} 1 \mathrm{X}$ Annexin V-FITC binding buffer and $10 \mu \mathrm{l}$ propidium iodide $(50 \mu \mathrm{g} / \mathrm{ml})$ were added to the cell suspension. The mixture was protected from light for $20 \mathrm{~min}$ for incubation at room temperature. Apoptosis was analyzed using BD FACS Canto II (BD Biosciences) and data were analyzed using BD FACSDiva software 7.0 (BD Biosciences). Early and late apoptotic cells were used to calculate the apoptotic rate.

Seahorse XF assay. Briefly, cells were seeded in XF cell culture plates (Agilent Technologies, Inc.) at a density of $3 \times 10^{4}$ cells/well and cultured at $37^{\circ} \mathrm{C}$ overnight. When cell monolayers were $\sim 90 \%$ confluent, the culture medium was replaced with bicarbonate-free low-buffered assay medium (XF Base Medium; Agilent Technologies, Inc.) supplemented with $10 \mathrm{mM}$ glucose, $2 \mathrm{mM}$ glutamine and $1 \mathrm{mM}$ pyruvate. Rotenone (cat. no. R105076; Shanghai Aladdin Bio-Chem Technology Co., Ltd.) at a final concentration of $0.5 \mu \mathrm{M}$ and bufalin at final concentrations of 10,20 and $40 \mu \mathrm{M}$ were loaded to reagent ports on the sensor cartridge and added during oxygen consumption rate (OCR) measurement. Cells were incubated in a non- $\mathrm{CO}_{2}$ incubator at $37^{\circ} \mathrm{C}$ for $1 \mathrm{~h}$ prior to testing. The OCR was detected by a Seahorse XF96 Analyzer (Agilent Technologies, Inc.) according to the manufacturer's instructions.

Mitochondria isolation. Mitochondria isolation was performed using a Cell Mitochondria Isolation kit (cat. no. C3601; Beyotime Institute of Biotechnology). Briefly, the cells were incubated with Mitochondria isolation reagent containing PMSF on ice for $15 \mathrm{~min}$. After Dounce homogenization, the suspension was centrifuged at $4^{\circ} \mathrm{C}$ and $1,000 \mathrm{x}$ g for $10 \mathrm{~min}$. Next, the supernatant was centrifuged at $4^{\circ} \mathrm{C}$ and $12,000 \mathrm{x} \mathrm{g}$ for $10 \mathrm{~min}$. The deposit (mitochondria) and supernatant (cytoplasm) were separately stored at $-80^{\circ} \mathrm{C}$.

Western blotting. Total protein was extracted from cells, which had been lysed with RIPA buffer (Cell Signaling Technology, Inc.). After denaturation and reductive alkylation, proteins (10 $\mu \mathrm{g} /$ lane, determined by BCA assay) were separated via $10 \%$ SDS-PAGE and transferred to polyvinylidene fluoride membranes (EMD Millipore). All blots were blocked via incubation in 5\% skimmed milk for $2 \mathrm{~h}$ at room temperature. After washing with $1 \mathrm{X}$ TBS-0.1\% Tween-20 buffer, primary antibodies were added to polyvinylidene fluoride membranes overnight at $4^{\circ} \mathrm{C}$. Polyclonal antibodies against voltage-dependent anion channel 1 (cat. no. 4866) and cleaved caspase-3 (cat. no. 9661), and monoclonal antibodies against cleaved PARP (cat. no. 5625), cytochrome $c$ (cat. no. 4280), Bax (cat. no. 5023), Bcl-2 (cat. no. 4223) and $\beta$-actin (cat. no. 4970) were acquired from Cell Signaling Technology, Inc. (all rabbit; all 1:1,000). Finally, horseradish peroxidase-conjugated secondary antibody (anti-rabbit; 1:1,000; cat. no. A0208; Beyotime Institute of Biotechnology) was added for $2 \mathrm{~h}$ at room temperature. All blots were visualized using BeyoECL Star reagent (cat. no. P0018AM; Beyotime Institute of Biotechnology) using a Bio-Rad ChemiDoc XRS+ (Bio-Rad Laboratories, Inc.).

Gel-based fluorescence and Coomassie blue staining of $S K-N-B E(2)$ cells in vitro. Cell lysates of SK-N-BE(2) were 
lysed in $0.2 \%$ SDS containing $1 \mathrm{X}$ protease inhibitor cocktail (Beyotime Institute of Biotechnology) and then treated with 30,60 or $120 \mu \mathrm{M} \mathrm{CS}-\mathrm{P} 1$ for $4 \mathrm{~h}$ in the dark at $37^{\circ} \mathrm{C}$, whereas control cells were treated with $0.1 \%$ DMSO. For competitive binding analysis, SK-N-BE(2) cell lysates were pretreated with $120 \mu \mathrm{M}$ bufalin $\left(37^{\circ} \mathrm{C}, 2 \mathrm{~h}\right)$ followed by $120 \mu \mathrm{M}$ CS-P1. After incubation on ice for $30 \mathrm{~min}$ and sonication at $4^{\circ} \mathrm{C}$ for $2 \mathrm{~min}$ at $30 \%$, the lysates were added to freshly prepared click reaction cocktail [200 $\mu \mathrm{M}$ azide-fluor 488 (Sigma-Aldrich; Merck KGaA), $1 \mathrm{mM}$ cupric sulfate $\left(\mathrm{CuSO}_{4}\right.$; Sangon Biotech Co., Ltd.), $2 \mathrm{mM}$ Tris(2-carboxyethyl)phosphine (TCEP; Sangon Biotech Co., Ltd.), $80 \mu \mathrm{M}$ Tris[(1-benzyl-1 H-1,2,3-triazol-4-yl)methyl]amine (TBTA; TCI Shanghai Development Co., Ltd.)], vortexed and incubated at room temperature for $1.5 \mathrm{~h}$. Finally, prechilled acetone was added to the mixture to terminate the reaction and precipitate the proteins. After centrifugation at $21,130 \mathrm{x} \mathrm{g}$ at $4^{\circ} \mathrm{C}$ for $2 \mathrm{~min}$ and washing with prechilled acetone twice, the pellet was re-dissolved in $1 \mathrm{X}$ SDS loading buffer, and $30 \mu \mathrm{g}$ of each sample was separated via $10 \%$ SDS-PAGE. The gel was completely covered by $0.25 \%$ Coomassie Blue R250 [cat. no. 20310ES25; Yeasen Biotechnology (Shanghai) Co., Ltd.] staining solution $(0.25 \%$ R250 dissolved in 50\% methanol, $10 \%$ acetic acid and $40 \%$ water) for $4 \mathrm{~h}$ in the dark and then washed with $5 \%$ methanol, $7.5 \%$ acetic acid and $87.5 \%$ water for $24 \mathrm{~h}$. Finally, the gel was analyzed using the Bio-Rad ChemiDoc XRS+.

Cellular imaging. A549 cells were seeded in 6-well plates containing sterile glass coverslips, and then treated with $20 \mu \mathrm{M}$ CS-P1 or DMSO for $4 \mathrm{~h}$ after the confluence reached $80 \%$. After removing the medium, prewarmed $\left(37^{\circ} \mathrm{C}\right)$ medium without FBS containing $500 \mathrm{nM}$ MitoTracker (cat. no. C1035; Beyotime Institute of Biotechnology) were added to plates for $30 \mathrm{~min}$ in a humidified incubator with $5 \% \mathrm{CO}_{2}$ at $37^{\circ} \mathrm{C}$. The cells were washed three times with PBS, and then treated with 4\% paraformaldehyde for $15 \mathrm{~min}$ at room temperature to fix the cells. After further washing for three times with PBS, the cells were permeabilized with $1 \%$ Triton X-100 for 15 min at room temperature, and then washed again with PBS. The cells were further incubated with freshly prepared click reaction cocktail for $1.5 \mathrm{~h}$ at room temperature with vigorous shaking, and then washed three times with PBS. Images (magnification, $\mathrm{x} 400$ ) were captured under a fluorescence microscope (Leica Microsystems GmbH).

Enrichment by azide magnetic beads. The SK-N-BE(2) cell lysates in $0.2 \%$ SDS with $1 \mathrm{X}$ protease inhibitor cocktail were pretreated with $120 \mu \mathrm{M}$ bufalin $\left(37^{\circ} \mathrm{C}, 2 \mathrm{~h}\right)$ followed by $120 \mu \mathrm{M} \mathrm{CS}-\mathrm{P} 1\left(37^{\circ} \mathrm{C}, 4 \mathrm{~h}\right)$ or DMSO $\left(37^{\circ} \mathrm{C}, 4 \mathrm{~h}\right)$. After incubation on ice for $30 \mathrm{~min}$ and sonication at $4^{\circ} \mathrm{C}$ for $2 \mathrm{~min}$ at $30 \%$, the lysates ( $400 \mu \mathrm{g}$ total protein) were added to freshly prepared click reaction cocktail $[10 \mu 1$ azide magnetic beads (Click Chemistry Tools), $1 \mathrm{mM} \mathrm{CuSO}{ }_{4}, 2 \mathrm{mM}$ TCEP and $80 \mu \mathrm{M}$ TBTA] for $1.5 \mathrm{~h}$ at room temperature with rotation. After reductive alkylation [100 $\mathrm{mM}$ ammonium bicarbonate $\left(\mathrm{NH}_{4} \mathrm{HCO}_{3}\right.$; Sangon Biotech Co., Ltd.) with $20 \mathrm{mM}$ TCEP and $40 \mathrm{mM}$ iodoacetamide (Sigma-Aldrich; Merck KGaA) for $1 \mathrm{~h}$ at room temperature in the dark], the beads were washed twice with $8 \mathrm{M}$ urea, followed by three washes with PBS. Next, the beads were resuspended with $200 \mu 1100 \mathrm{mM} \mathrm{NH}_{4} \mathrm{HCO}_{3}$ containing $4 \mu \mathrm{g}$ trypsin (Promega Corporation) and incubated at $37^{\circ} \mathrm{C}$ overnight. Finally, the supernatant was collected and desalted using a ZipTip with $0.6 \mu 1 \mathrm{C} 18$ column (5 $\mu \mathrm{g}$; cat. no. ZTC18S960; Millipore). After drying in a speed-vac, samples were stored at $-80^{\circ} \mathrm{C}$ prior to MS analysis. Each treated sample was prepared in three biological replicates.

Nano-high-performance liquid chromatography (HPLC)-MS/MS analysis. Q Exactive plus (Thermo Fisher Scientific, Inc.) coupled to an U300 RSLCnano system (Thermo Fisher Scientific, Inc.) was used to conduct Nano-HPLC-MS/MS analysis at room temperature. Briefly, tryptic peptide fragments of proteins were dissolved in solvent A ( $0.1 \%$ formic acid, $2 \%$ acetonitrile and $98 \% \mathrm{H}_{2} \mathrm{O}$ ). Separation was performed over a linear gradient of $5-35 \%$ solvent $\mathrm{B}$ $\left(0.1 \%\right.$ formic acid, $90 \%$ acetonitrile and $10 \% \mathrm{H}_{2} \mathrm{O}$ ) for $50 \mathrm{~min}$ and $35-80 \%$ for another $10 \mathrm{~min}$ at a constant flow rate of $300 \mathrm{nl} / \mathrm{min}$ on a manually packed reversed phase C18 column (170 mm x $79 \mu \mathrm{m}, 3-\mu \mathrm{m}$ particle size; Dikma Technologies, Inc.) coupled to an U300 RSLCnano chromatography system. The eluted peptides were ionized and analyzed with a Q Exactive plus mass spectrometer using a nanospray ion source. For full MS spectra, peptides ranging from 350-1,300 m/z were scanned in an Orbitrap at a resolution of 120,000 at $\mathrm{m} / \mathrm{z} 200$. Automatic gain control was set to 7,000 at rapid mode with $1 \mathrm{~m} / \mathrm{z}$ isolation window. Higher energy collisional dissociation was sequentially used to fragment ions with charge states $2+, 3+$ and $4+$ at a normalized collision energy of $32 \%$. The dynamic exclusion duration was set to $60 \mathrm{sec}$. Fragment ions were analyzed in a linear ion trap.

MS data analysis. MaxQuant software (version 1.6.0.16) (19) was used for peak detection and quantification for MS raw files. Raw data were searched against the UniProt Human database (https://www.uniprot.org/uniprot/?query=organism:960 $6 \&$ sort=score) using the Andromeda search engine (20), with cysteine alkylation by iodoacetamide as a fixed modification, and methionine oxidation, Lys6, and Arg10, protein N-terminal acetylation as variable modifications. The proteolytic enzyme was trypsin and maximum missing cleavages was 2 . After searching using a mass tolerance of $20 \mathrm{ppm}$, the mass accuracy of the precursor ions in the main search was $4.5 \mathrm{ppm}$ and fragment ion mass tolerance was $0.02 \mathrm{Da}$ for Q-Exactive or $0.5 \mathrm{Da}$ for Fusion. The maximum false discovery rate was 0.01 for proteins and peptides, and a minimum peptide length of seven amino acids was required. Proteins identified in three replicates were considered as significant targets if they met the following criteria: i) Only detected in the CS-P1 group but not in the DMSO group; and ii) had at least one unique peptide.

Bioinformatics analysis. The Database for Annotation, Visualization and Integrated Discovery (https://david.ncifcrf. gov/) v6.8 was used for bioinformatics analysis. The candidates identified by chemical proteomics were annotated by Gene Ontology (GO) analysis $(21,22)$. The threshold conditions were set to a count $\geq 5$ and EASE score (a modified Fisher's exact $\mathrm{P}$-value) $\leq 0.05$.

Subcutaneous xenograft model in nude mice. A total of 10 male nude mice (6 weeks, $18-22 \mathrm{~g}$ ) were purchased 
from the Shanghai Laboratory Animal Center of the Chinese Academy of Sciences. Mice were housed under specific pathogen-free conditions (humidity, 40-70\%; temperature, $22 \pm 2{ }^{\circ} \mathrm{C} ; 12: 12$-h light/dark cycle; free access to standard sterile food and water). Ethical approval for animal experiments was obtained from the Xinhua Hospital Ethics Committee (Shanghai, China; approval no. XHEC-F-2020-011). The xenograft study was performed between February 2020 and April 2020. SK-N-BE(2) cells $\left(5 \times 10^{6}\right.$ cells in $100 \mu \mathrm{l}$ PBS $)$ were injected subcutaneously into the left axilla of each mouse. The mice were randomly divided into two groups (5 mice/group) and treated as follows: Group one, vehicle (90\% of 10\% 2-hydroxypro pyl- $\beta$-cyclodextrin mixed with $10 \%$ DMSO) was injected intraperitoneally alone; and group two, bufalin $(5 \mathrm{mg} / \mathrm{kg})$ was dissolved in vehicle and injected intraperitoneally three times every week. Humane endpoints were set as the tumor volume exceeding $2,000 \mathrm{~mm}^{3}$ or the maximum diameter of a tumor exceeding $2 \mathrm{~cm}$, at which point nude mice would be euthanized. However, no mice were euthanized or found dead before the end of the 4 -week treatment period. The nude mice were checked when receiving treatment. Tumor volumes were measured every week and calculated as $1 / 2 \times$ width $^{2} \mathrm{x}$ length. The xenograft tumors were excised (fixed in $4 \%$ paraformaldehyde at $4^{\circ} \mathrm{C}$ overnight) and weighed after 4 weeks of treatment. Nude mice were euthanized with carbon dioxide $(30 \%$ volume/min chamber displacement) until breathing stopped for $2 \mathrm{~min}$, and then cervical dislocation was performed to ensure death.

Immunohistochemistry staining. Immunohistochemistry staining for Ki67, proliferating cell nuclear antigen (PCNA) and caspase-3 was performed by Servicebio, lnc. Images (magnifications, $\mathrm{x} 100, \mathrm{x} 200$ and $\mathrm{x} 400$ ) were acquired under an optical microscope (Leica Microsystems $\mathrm{GmbH}$ ) and five randomly selected fields were analyzed. A semiquantitative histological score (H-score) was applied for the evaluation of the immunohistochemistry staining results. The H-score considers both the degree of staining intensity and the percentage of positive neoplastic cells. The intensity was scored on a scale of 0 to 3 ( 0 , negative; 1 , weak; 2 , medium; and 3 , strong). The formula for the H-score is as follows: $\mathrm{H}$-score $=\sum(\mathrm{Pi} \times \mathrm{I})=($ percentage of cells with weak intensity $\mathrm{x} 1)+$ (percentage of cells with moderate intensity $\mathrm{x} 2)+($ percentage of cells with strong intensity x3) (23), where Pi indicates the percentage of positive tumor cells and I indicates staining intensity.

Statistical analysis. Statistical analysis was conducted using Prism 6 software (GraphPad Software, Inc.). Unpaired student's t-test was used to analyze differences between two groups. One-way ANOVA was used to analyze datasets containing $\geq 3$ groups and Tukey's multiple comparisons test was used following one-way ANOVA to determine significant differences between specific groups. Two-way ANOVA was used to analyze datasets where groups were divided by two factors, and Sidak's multiple comparisons test was used following two-way ANOVA. Experiments were conducted independently at least three times and the results are presented as the mean \pm SD. $\mathrm{P}<0.05$ was considered to indicate a statistically significant difference.

\section{Results}

Bufalin inhibits the proliferation and migration of neuroblastoma cells. The antitumor effects of bufalin in neuroblastoma were evaluated. As shown in Fig. 1A, cell proliferation was markedly suppressed by bufalin in dose-(1-1,000 nM) and time-dependent $(24,48$ or $72 \mathrm{~h})$ manners. The $\mathrm{IC}_{50}$ values of bufalin in SK-N-BE(2) and SH-SY5Y cells were $~ 90$ and $30 \mathrm{nM}$ at $72 \mathrm{~h}$, respectively (Fig. 1B), and the cells were selected for the subsequent experiments. Single-cell proliferation and viability was investigated in a colony formation assay. As shown in Fig. 1C-F, the number and size of colonies formed by neuroblastoma cells treated with bufalin were significantly reduced. Additionally, Transwell assays showed that the ability to migrate to the lower chambers was significantly suppressed in SK-N-BE(2) and SH-SY5Y cells upon exposure to bufalin (Fig. 1G-J). Together, these results indicated antitumor properties of bufalin in neuroblastoma by inhibiting cell proliferation and migration.

Bufalin probe CS-P1 retains the antitumor activity of bufalin in neuroblastoma. Identifying potential protein targets is the first step towards understanding the molecular mechanism underlying the antitumor activity of bufalin. Bufalin is a cardiotonic steroid with an $\alpha, \beta$-unsaturated carbonyl group (24). Through the electron-withdrawing effect of the oxygen atom, $\alpha, \beta$-unsaturated carbonyl is prone to attack by nucleophiles for Michael additions, such as thiol and amido (25). The results suggested that bufalin reacted with peptide molecules (Fig. S1A-E). To further investigate the cellular target proteins of bufalin, the alkyne-containing chemical probe CS-P1 was designed and synthesized (Fig. 2A). The biological activity of CS-P1 was first assessed in the A549 cell line, a positive control with an $\mathrm{IC}_{50}<10 \mathrm{nM}$ for bufalin (26). Incubation of A549 cells with CS-P1 for $24 \mathrm{~h}$ significantly reduced the viability of $\mathrm{A} 549$ cells, showing an $\mathrm{IC}_{50}$ of $104.7 \mathrm{nM}$, while bufalin exhibited an $\mathrm{IC}_{50}$ of $9.8 \mathrm{nM}$ (Fig. S1F). Intracellular localization of CS-P1 was visualized by Azide-fluor 488 and mitochondria were found to be potential targets (Fig. S1G). Subsequently, the antitumor activity of CS-P1 was evaluated in neuroblastoma cells. As shown in Fig. 2B, the 72-h $\mathrm{IC}_{50}$ of CS-P1 in SK-N-BE(2) cells was $329 \mathrm{nM}$, revealing that, similar to bufalin, CS-P1 exhibited antitumor properties at nanomolar concentrations. In addition, colony formation assays and cell migration assays demonstrated that CS-P1 suppressed neuroblastoma cell proliferation and migration (Fig. S2). Gel staining indicated potential targets shared by CS-P1 and bufalin. In brief, total proteins of SK-N-BE(2) cells pretreated with bufalin and CS-P1 together or CS-P1 only were subjected to a click reaction with Azide-fluor 488, and then resolved by SDS-PAGE. Only CS-P1-targeted proteins were fluorescently labeled, and the density of the sample co-treated with bufalin and CS-P1 was markedly decreased (Fig. 2C). These results suggested that CS-P1 retains antitumor properties by competitively binding to the targets of bufalin.

Chemical proteomics highlights the ETC as a potential target. Next, the potential antitumor targets shared by bufalin and CS-P1 were investigated using a chemical proteomics strategy as shown in Fig. 3A. Briefly, after pretreatment with bufalin, 


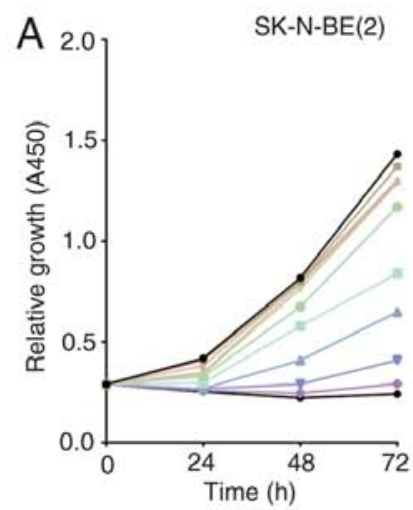

- NC

$-2.5 \mathrm{nM}$

$-5 \mathrm{nM}$

$25 \mathrm{nM}$

$25 \mathrm{nM}$

$+100 \mathrm{nM}$

$-250 \mathrm{nM}$

$-1000 \mathrm{nM}$

C

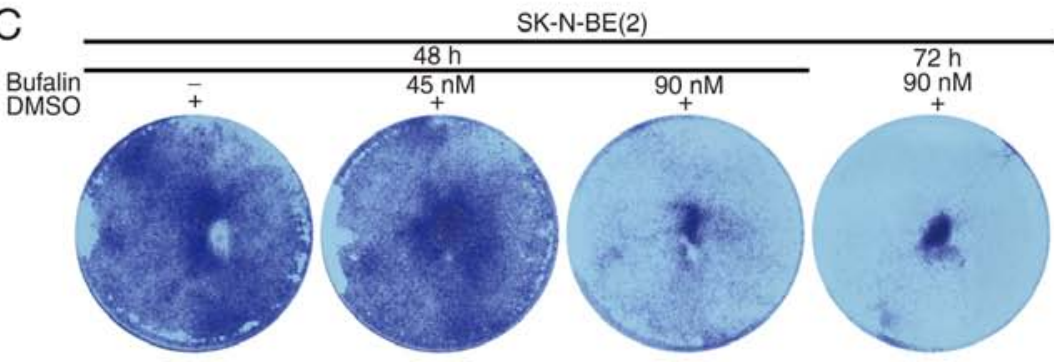

E
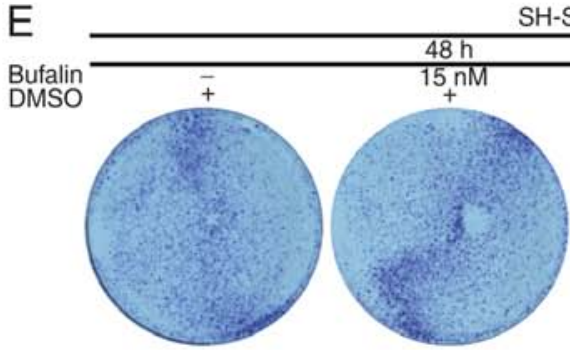

SH-SY5Y
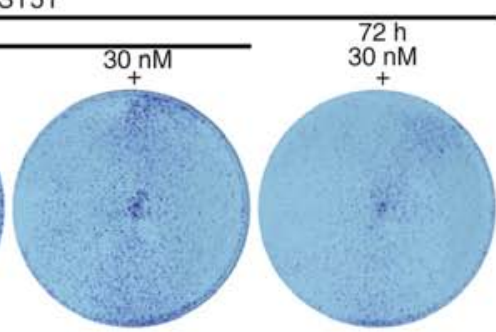

G

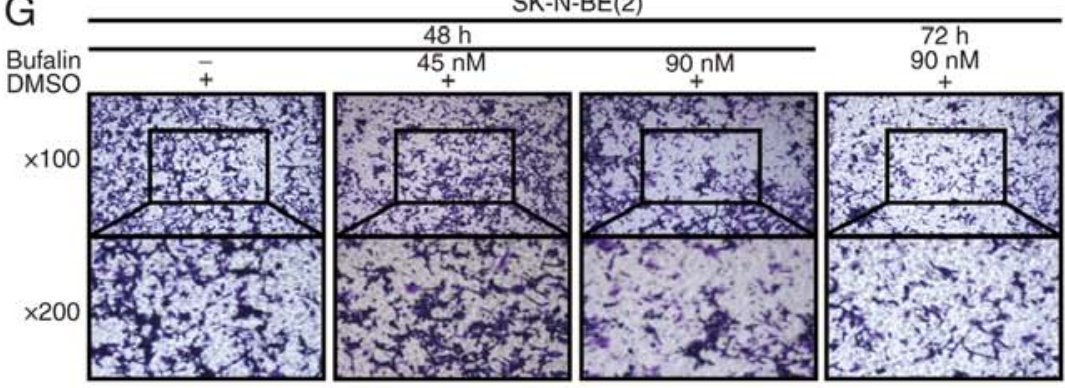

I

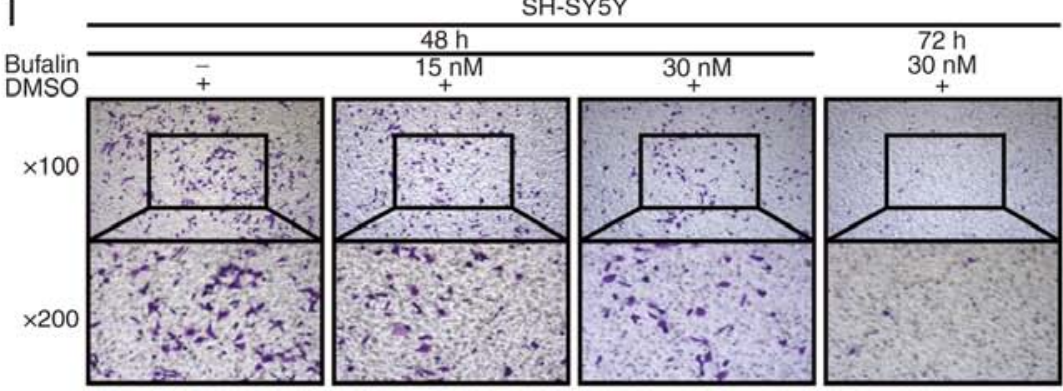

B
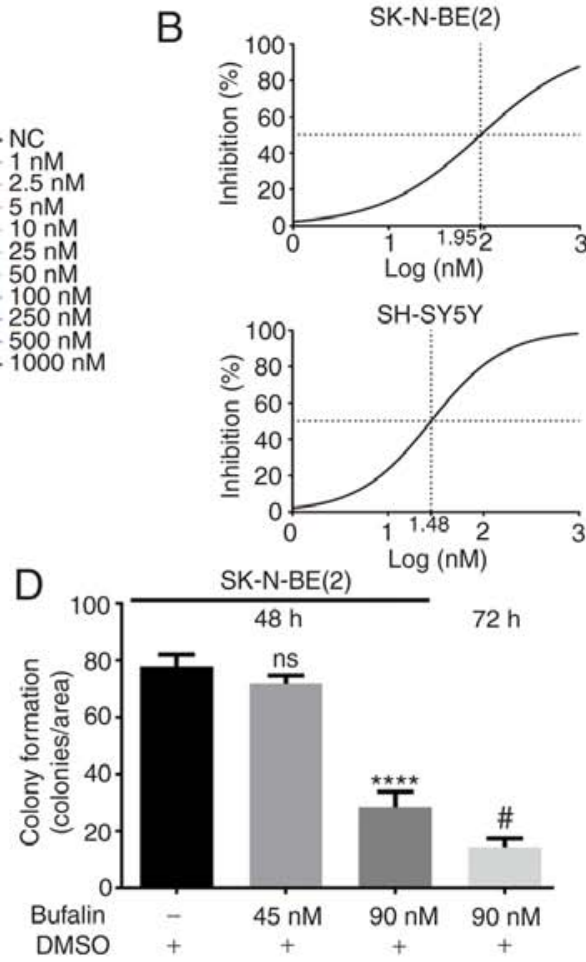

F
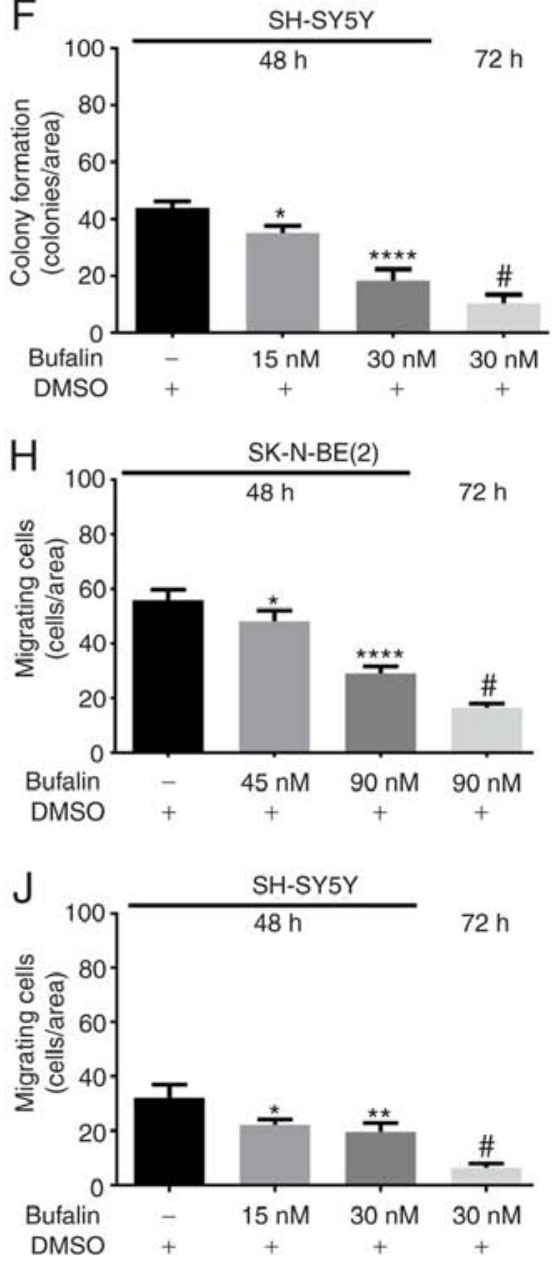

Figure 1. Bufalin inhibits the proliferation and migration of neuroblastoma cells. (A) Relative growth of SK-N-BE(2) and SH-SY5Y cells represented as A450, indicating dose- and time-dependent antitumor effects of bufalin. (B) $\mathrm{IC}_{50}$ of SK-N-BE(2) and SH-SY5Y at $72 \mathrm{~h}$. (C) Colony formation assay of SK-N-BE(2) cells and (D) histogram of colonies. (E) Colony formation assay of SH-SY5Y cells and (F) histogram of colonies. (G) Transwell migration assay of SK-N-BE(2) cells and (H) histogram of cell migration. (I) Transwell migration assay of SH-SY5Y cells and (J) histogram of cell migration. Magnifications, x100 and x200. Data are presented as the mean $\pm \mathrm{SD}(\mathrm{n}=3) .{ }^{*} \mathrm{P}<0.05,{ }^{* *} \mathrm{P}<0.01$ and ${ }^{* * * * *} \mathrm{P}<0.0001$ vs. DMSO; ${ }^{\#} \mathrm{P}<0.05 \mathrm{vs} .48 \mathrm{~h} / 90 \mathrm{nM}$ or $48 \mathrm{~h} / 30 \mathrm{nM}$. A450, absorbance at $450 \mathrm{~nm}$; DMSO, dimethyl sulfoxide; $\mathrm{IC}_{50}$, half maximal-inhibitory concentration; $\mathrm{NC}$, negative control; ns, not significant. 
A

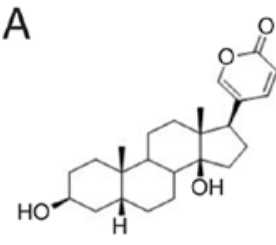

Bufalin

B

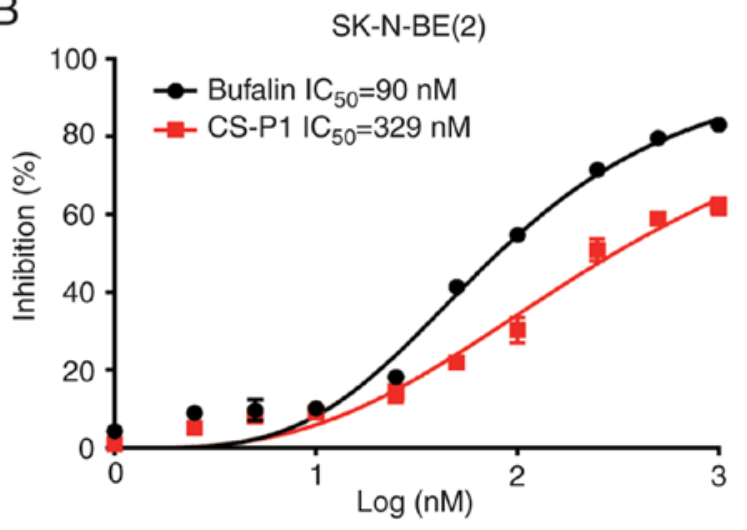

CS-P1

SK-N-BE(2)
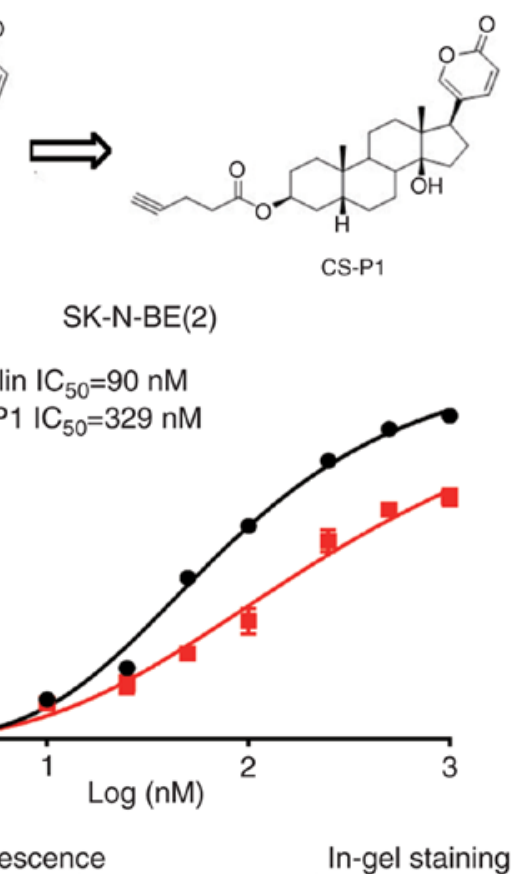
(coomassie blue)

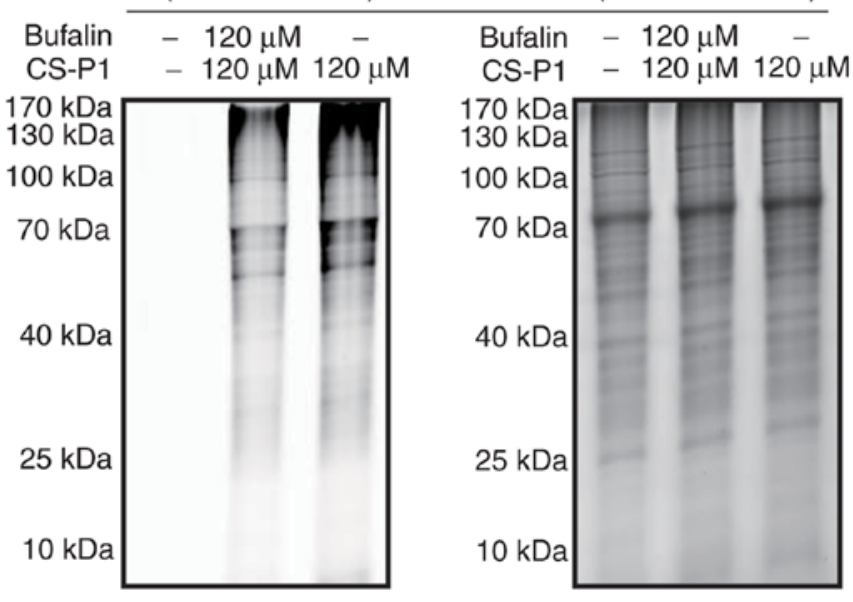

Figure 2. Bufalin probe CS-P1 retains the antitumor activity of bufalin in neuroblastoma. (A) Chemical structure of bufalin and CS-P1. (B) Comparison of antitumor efficacy of bufalin and CS-P1. (C) In-gel fluorescence (azide-fluor 488); targeted proteins were fluorescently labeled. When co-incubated with bufalin and CS-P1, fluorescence was decreased. In-gel staining with Coomassie blue was used as a control. Data are presented as the mean \pm SD $(\mathrm{n}=3) . \mathrm{IC}_{50}$, half maximal-inhibitory concentration.

proteins were then treated with CS-P1 or DMSO. Proteins only detected in the CS-P1 group but not the DMSO group were considered to be targets. A total of 99 proteins were identified in three replicates (Fig. 3B and Table SI). According to the fluorescence imaging shown in Fig. S1G, mitochondria-derived proteins were hypothesized to be potential targets. GO term analysis was performed to annotate the cellular localization of the identified proteins (Fig. 3C). 'Mitochondrial inner membrane' (GO:0005743) was enriched according to the conditions of count $\geq 5$ and a maximum EASE score of 0.05 . There were 7 targets identified that fell under the term 'mitochondrial inner membrane', including CDS2, SDHD, COX7C, TMEM126A, MRPS31, MRPL34 and ATP5J, several of which were localized to the ETC, suggesting that ETC disruption occurred upon exposure to bufalin (Fig. 3D). Disruption of the ETC would decrease the OCR of cells, which was validated by performing a Seahorse assay after administration of bufalin in SK-N-BE(2) cells (Fig. 3E and F). It was previously reported that ETC disruption led to excessive ROS levels (27). Therefore, ROS levels were increased in SK-N-BE(2) cells after treatment with CS-P1 (Fig. 3G and $\mathrm{H}$ ). Increased ROS levels reduce the $\Delta \Psi \mathrm{m}$ (28). As shown in Fig. 3I and $\mathrm{J}$, the $\Delta \Psi \mathrm{m}$ of SK-N-BE(2) cells was significantly reduced following treatment with CS-P1. These results suggested that bufalin induces its antitumor effects by targeting the ETC.

ETC disruption induces mitochondria-dependent apoptosis of neuroblastoma cells. Reductions in $\Delta \Psi \mathrm{m}$ result in cell apoptosis (29). To investigate the apoptotic effects of bufalin in neuroblastoma cells, flow cytometric analysis was performed for SK-N-BE(2) and SH-SY5Y cells. Compared with that in negative control cells, the apoptotic rate was significantly increased in bufalin-treated cells in dose- and time-dependent manners (Fig. 4A-D). Additionally, intracellular ROS levels were significantly increased after treatment with bufalin, which was consistent with the results described above (Fig. 4E-H). A decreased $\Delta \Psi$ m can lead to increased permeability of the mitochondrial membrane, causing cytochrome $c$ to flow from the mitochondria into the cytoplasm (30). Cytochrome $c$ may activate and cleave caspase- 3 via induction of the apoptotic cascade reaction by forming apoptosomes (31). Western blot analysis verified that cytochrome $c$ was decreased in the mitochondria but increased in the cytoplasm after treatment with bufalin (Fig. 4I). Moreover, downregulation of Bcl-2, as well as upregulation of Bax, cleaved caspase-3 and cleaved PARP, was observed following bufalin treatment (Fig. 4J).

Bufalin-induced apoptosis of neuroblastoma cells depends on ROS accumulation. To investigate whether ROS play a central role in the bufalin-induced apoptosis of neuroblastoma cells, $\mathrm{N}$-acetyl-L-cysteine (NAC), a well-known antioxidant, was used to inhibit the effects of ROS. Neuroblastoma cells were treated with NAC prior to exposure to bufalin. As shown in Fig. 5A-D, the increase in intracellular ROS levels following treatment with bufalin was significantly reversed by NAC in SK-N-BE(2) and SH-SY5Y cells. Additionally, the apoptotic rate of cells pretreated with NAC was significantly reduced compared with that of cells treated with bufalin alone (Fig. 5E-H).

Bufalin inhibits tumor growth in vivo. To establish animal models, SK-N-BE(2) cells were injected into nude mice subcutaneously. Next, bufalin or vehicle was intraperitoneally injected after cell transplantation. Tumor weight and volume in the treatment group were significantly decreased compared with the control group (Fig. 6A-C). To further investigate the mechanisms underlying these effects, immunohistochemical analysis was performed. As shown in Fig. 6D-G, the expression levels of the proliferation indicators Ki67 and PCNA were significantly decreased. Consistent with the in vitro results, caspase-3 expression was significantly increased.

\section{Discussion}

In various Asian Pacific countries, bufalin is used as a cardiac glycoside for heart failure treatment, and low-dose bufalin 

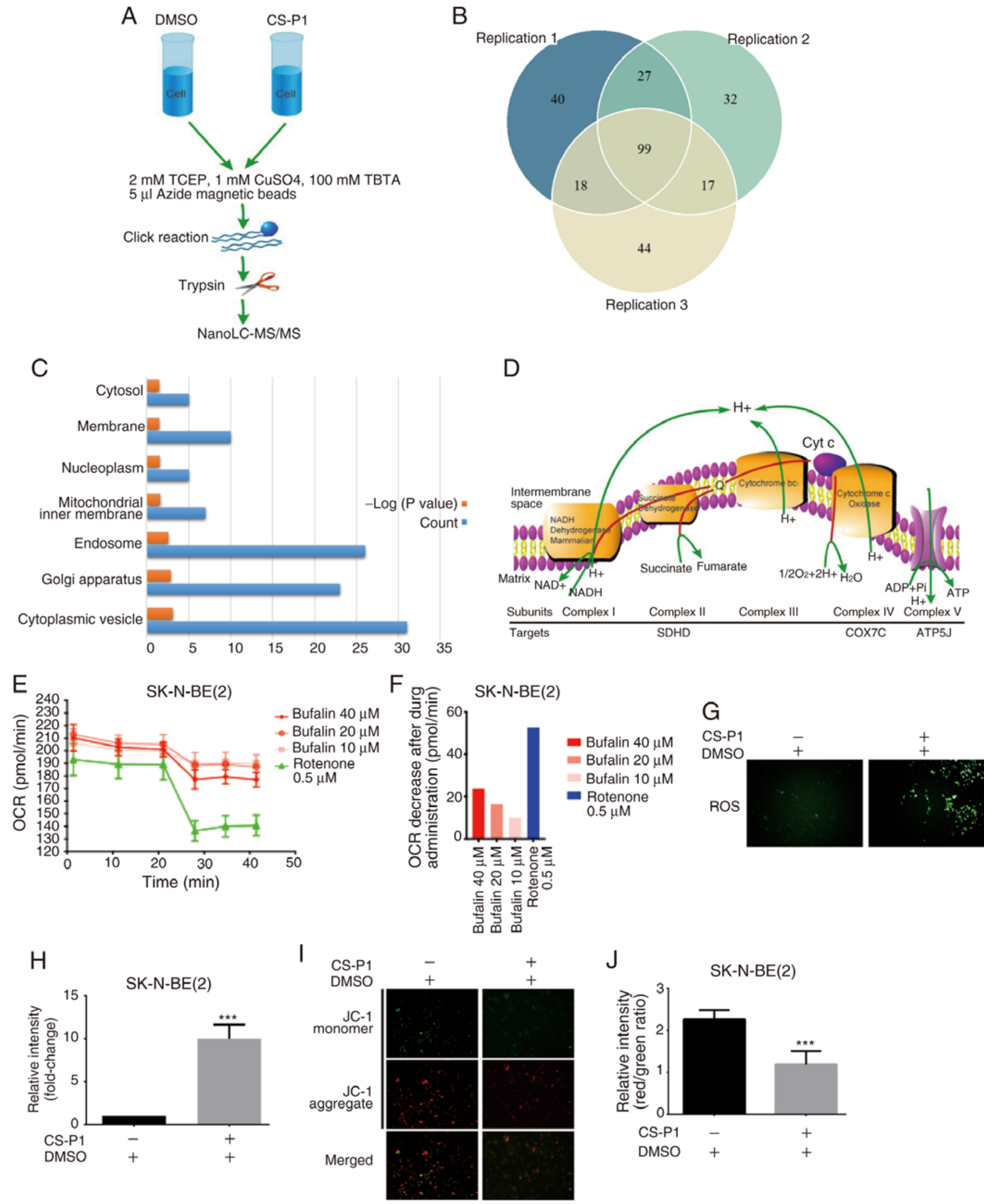

Figure 3. Chemical proteomics highlights the ETC as a potential target. (A) Workflow diagram of nanoLC-MS/MS. (B) Venn diagram of proteins identified in three experimental repeats. (C) Gene Ontology analysis annotated cellular components enriched by CS-P1. (D) Diagram of ETC and the possible targets of CS-P1. (E) Seahorse assay of oxygen consumption and (F) OCR decrease after administration of bufalin in SK-N-BE(2) cells. Rotenone was used as a positive control. (G) Intracellular ROS detection and (H) increase in ROS levels after CS-P1 treatment (329 nM, $72 \mathrm{~h}$; magnification, x200). (I) Mitochondrial membrane potential detection with JC-1 probes and (J) reduction after CS-P1 treatment (329 nM, $72 \mathrm{~h}$; magnification, x200). Data are presented as the mean $\pm \mathrm{SD}(\mathrm{n}=3){ }^{* * * *} \mathrm{P}<0.001$ vs. DMSO. ATP5J, ATP synthase-coupling factor 6; COX7C, cytochrome $c$ oxidase subunit 7C; DMSO, dimethyl sulfoxide; ETC, electron transport chain; LC-MS/MS, liquid chromatography-tandem mass spectrometry; OCR, oxygen consumption rate; ROS, reactive oxygen species; SDHD, succinate dehydrogrenase complex subunit D; TBTA, Tris[(1-benzyl-1H-1,2,3-triazol-4-yl)methyl]amine; TCEP, Tris(2-carboxyethyl) phosphine. 
A

A
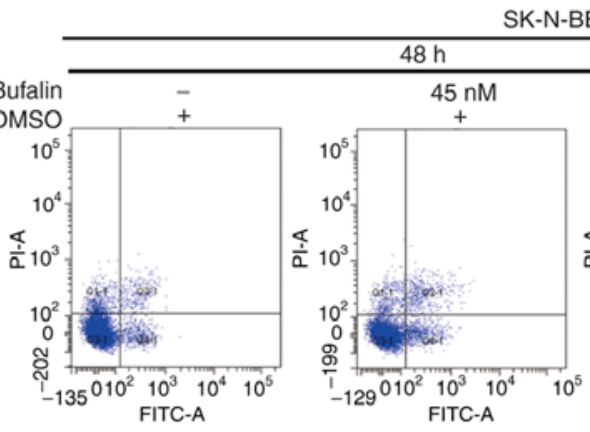

SK-N-BE(2)
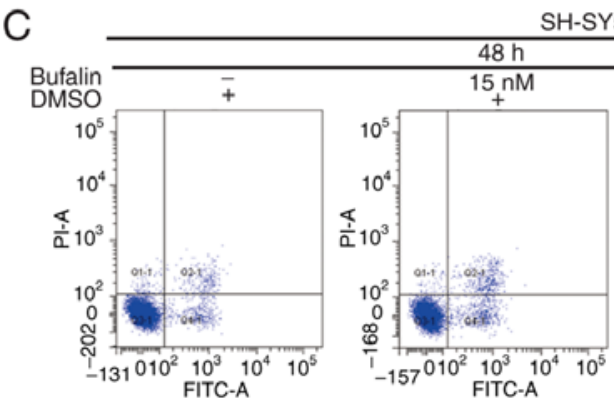

SH-SY5Y
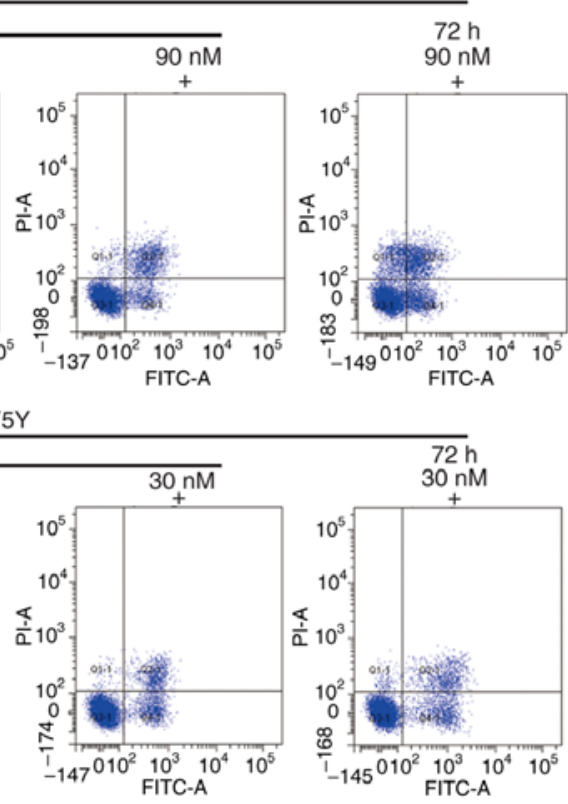

E
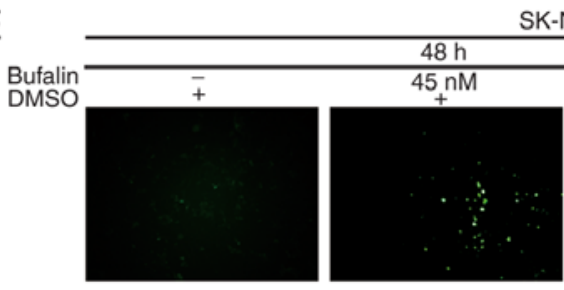

$\mathrm{K}-\mathrm{N}-\mathrm{BE}(2)$
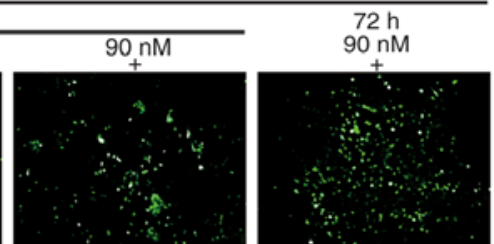

G
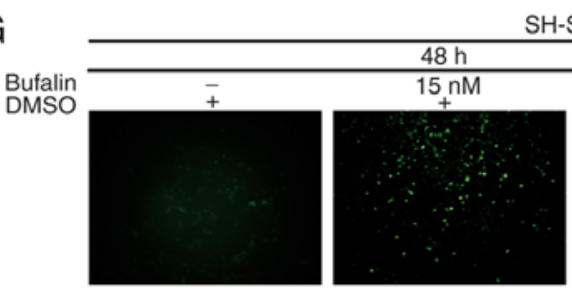

SH-SY5Y

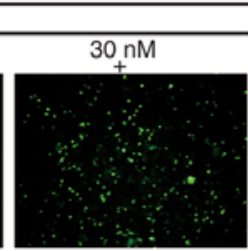

\section{I}
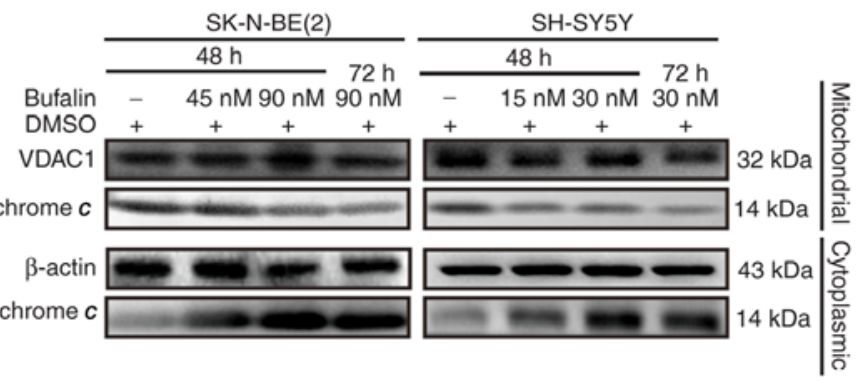

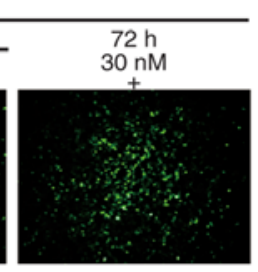

J

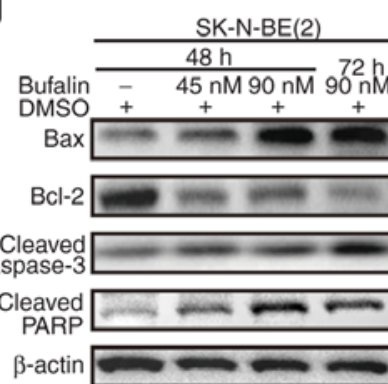

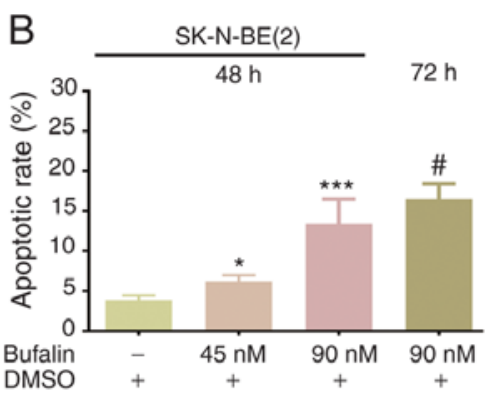
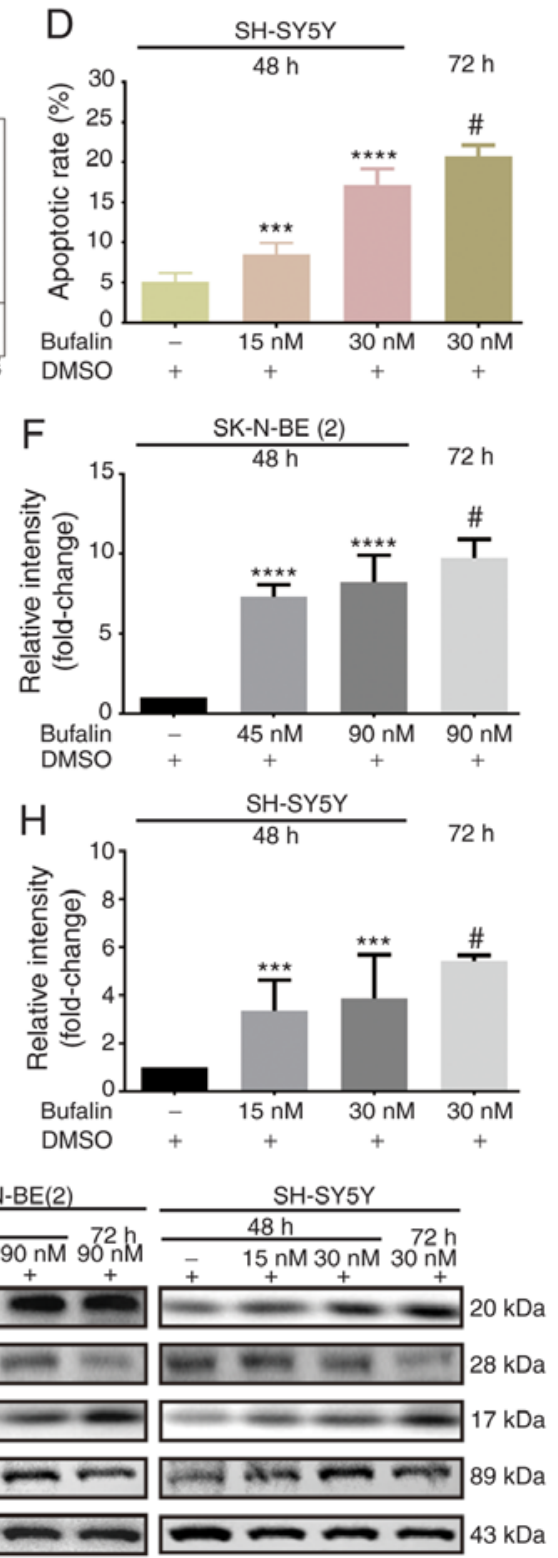

Figure 4. Electron transport chain disruption induces mitochondria-dependent apoptosis of neuroblastoma cells. (A) Flow cytometry analysis of SK-N-BE(2) cells and (B) apoptotic rate following bufalin treatment. (C) Flow cytometry analysis of SH-SY5Y cells and (D) apoptotic rate following bufalin treatment. (E) Intracellular ROS detection in SK-N-BE(2) cells and (F) increase in ROS levels after bufalin treatment. (G) Intracellular ROS detection in SH-SY5Y cells and (H) increase in ROS levels after bufalin treatment (magnification, x200). (I) Western blot analysis of cytochrome $c$ levels in mitochondria and cytoplasm after bufalin treatment. (J) Bax, Bcl-2, cleaved caspase-3 and cleaved PARP expression levels detected via western blotting. Data are presented as the mean $\pm \mathrm{SD}(\mathrm{n}=3) .{ }^{*} \mathrm{P}<0.05,{ }^{* * *} \mathrm{P}<0.001,{ }^{* * * * *} \mathrm{P}<0.0001$ vs. DMSO; ${ }^{\sharp} \mathrm{P}<0.05$ vs. $48 \mathrm{~h} / 90 \mathrm{nM}$ or $48 \mathrm{~h} / 30 \mathrm{nM}$. DMSO, dimethyl sulfoxide; PARP, poly(ADP-ribose) polymerase; PI, propidium iodide; ROS, reactive oxygen species; VDAC1, voltage-dependent anion channel 1.

does not cause fatal damage to the human body (32-34). Following reports that bufalin could potently induce the differentiation of human leukemia-derived cell lines (35), bufalin has subsequently been reported to induce antitumor effects in various types of tumor $(13,36,37)$. The octreotide-conjugated polymeric prodrug of bufalin has shown promising effects on somatostatin receptor 2-overexpressing breast cancer (38). Bufalin-loaded calcium phosphate/DPPE-polyethylene 
A
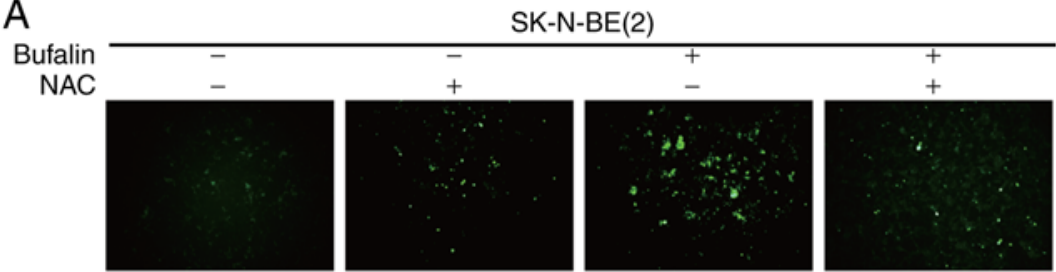

C
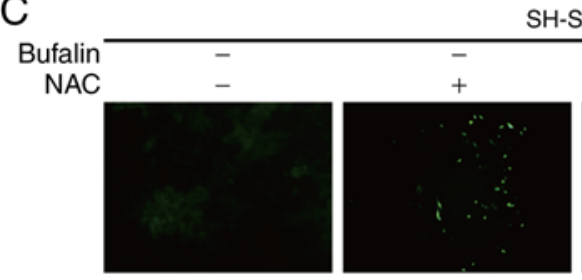

SH-SY5Y
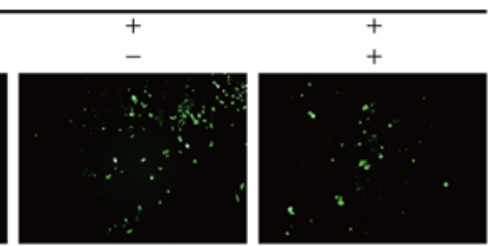

E

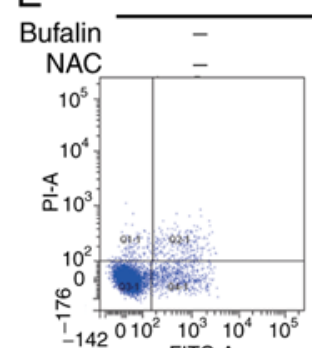

G

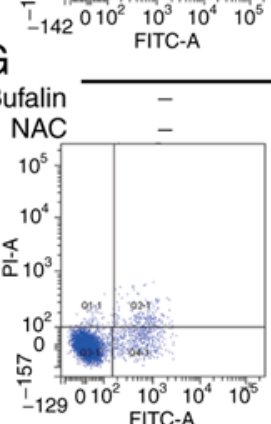

SK-N-BE(2)

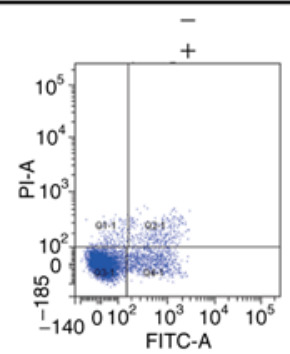

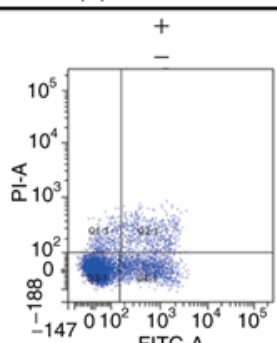

SH-SY5Y
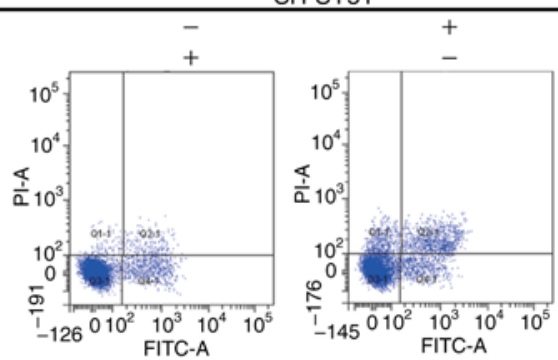

$\mathrm{B}$

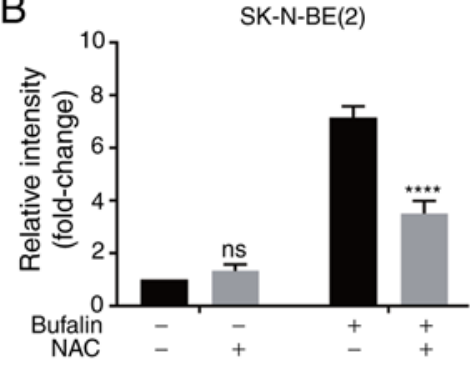

D

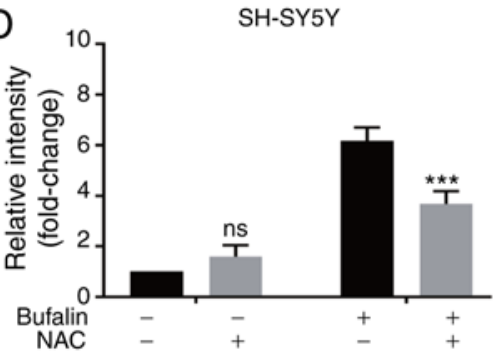

$\mathrm{F}$

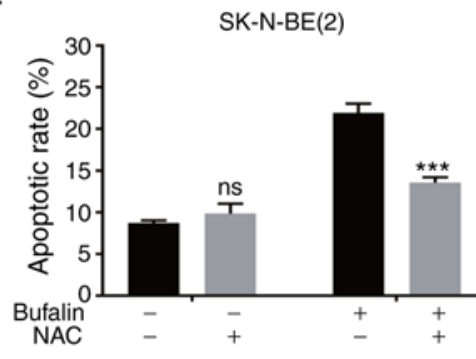

$\mathrm{H}$
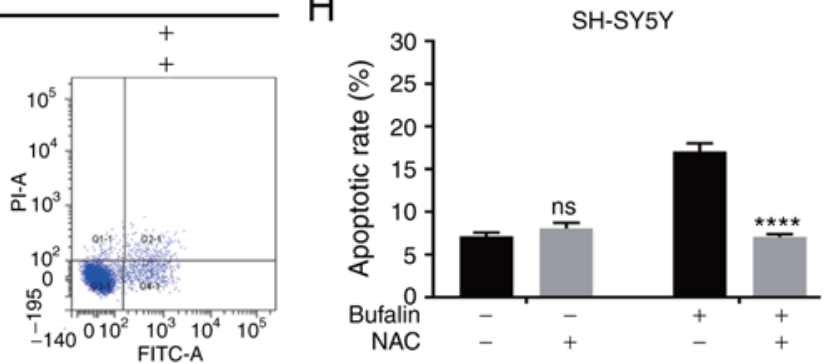

Figure 5. Bufalin-induced apoptosis of neuroblastoma cells depends on ROS accumulation. (A) Intracellular ROS detection in SK-N-BE(2) cells and (B) decrease in ROS levels following NAC treatment. (C) Intracellular ROS detection in SH-SY5Y cells and (D) decrease in ROS levels following NAC treatment (magnification, $x 200$ ). (E) Flow cytometry analysis of SK-N-BE(2) cells and (F) decrease in apoptotic rate following NAC treatment. (G) Flow cytometry analysis of SH-SY5Y cells and $(\mathrm{H})$ decrease in apoptotic rate following NAC treatment. Data are presented as the mean $\pm \mathrm{SD}(\mathrm{n}=3) .{ }^{* * * *} \mathrm{P}<0.001,{ }^{* * * * *} \mathrm{P}<0.0001$ vs. bufalin. NAC, N-acetyl-L-cysteine; ns, not significant compared with negative control; PI, propidium iodide; ROS, reactive oxygen species.

glycol-epidermal growth factor nanospheres were reported to have antitumor effects in colon cancer via slow release from dialysis membranes (39). Bufalin inhibits cell proliferation and induces apoptosis via DNA damage, chromatin condensation and endoplasmic reticulum stress (37,40-42). However, there remains limited knowledge regarding the potential mechanisms of bufalin, and the substrates of bufalin remain unknown, which hinders our further understanding of the molecular mechanism underlying its antitumor effects, as well as its potential toxicity. Thus, identifying the targets of bufalin is the first step towards its development as an antitumor drug.

Chemical probes and chemical proteomics provide an effective approach for identifying the potential cellular targets of bioactive compounds, including approved drugs (43). Exploring novel targets may expand our knowledge and avoid the potential side effects of these compounds $(44,45)$.
Therefore, a bufalin-derived probe was designed to investigate its potential targets by modifying with an alkyne group, enabling the probe to be immobilized with azide magnetic beads through a click chemical reaction. Thus, the potential targets of bufalin could be precipitated via pulldown. Cell viability assays showed that the modified probe retained the potent antitumor activity of bufalin. Chemical proteomics and bioinformatics analyses revealed the ETC as a direct target of bufalin. Downstream functional experiments suggested that ETC function was impaired, leading to ROS burst and a reduction in $\Delta \Psi \mathrm{m}$, as well as apoptosis. Collectively, the present findings identified respiratory chain proteins as potential substrates of bufalin. However, due to the limited specificity and accuracy of the probe, other directly targeted proteins remain unclear. In addition, how the compound binds to substrate proteins remains unclear, as well as which domain 
A
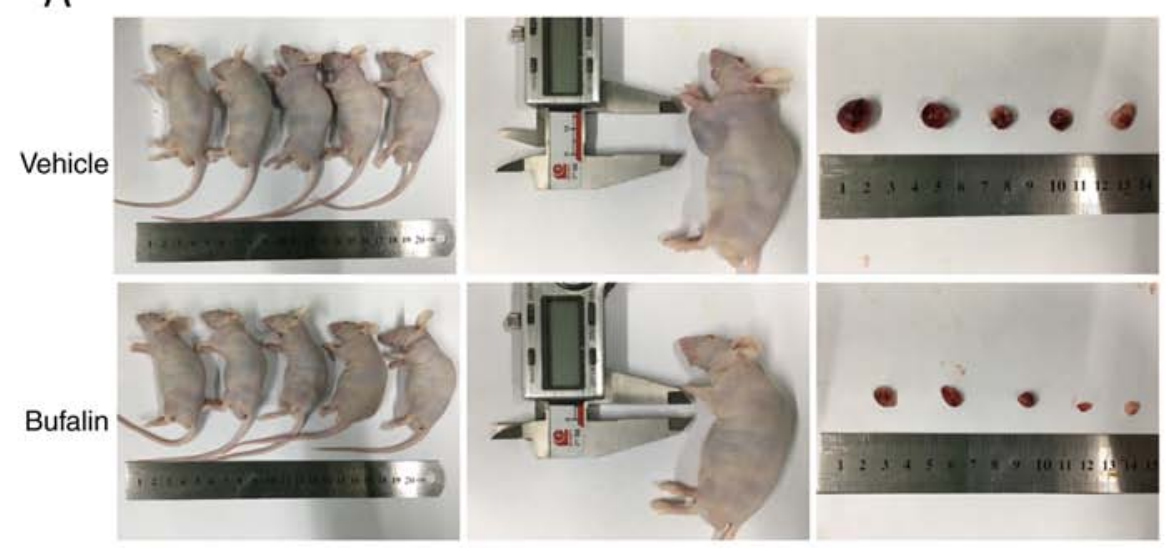

B

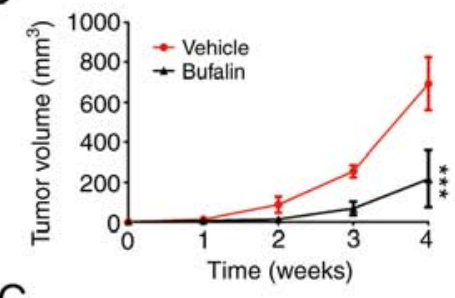

C

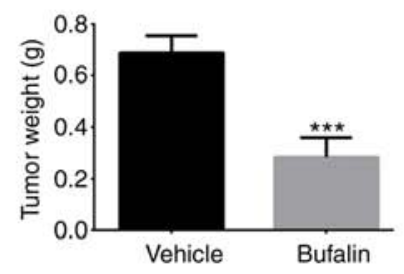

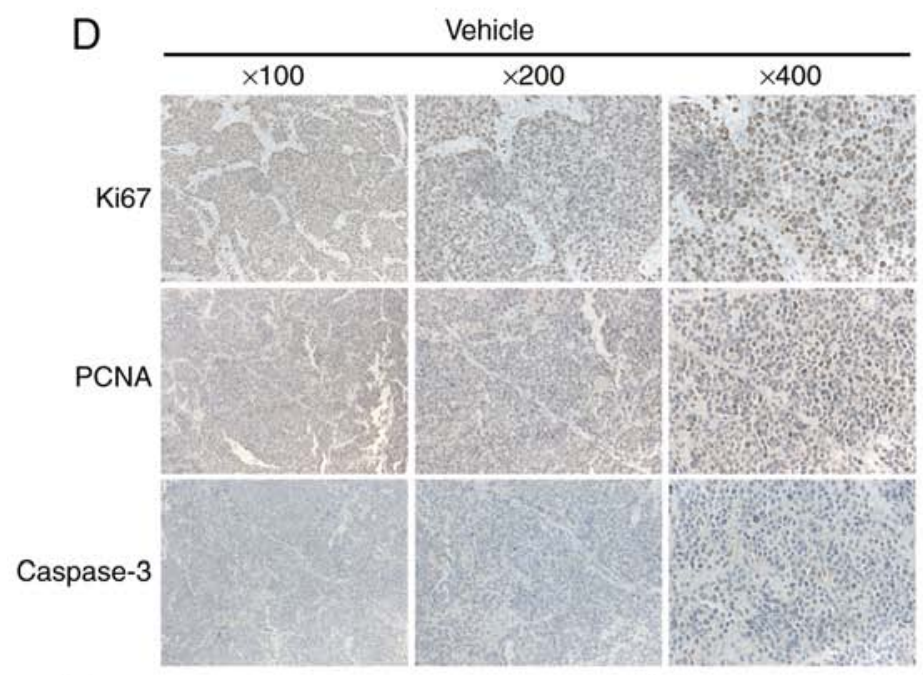

E

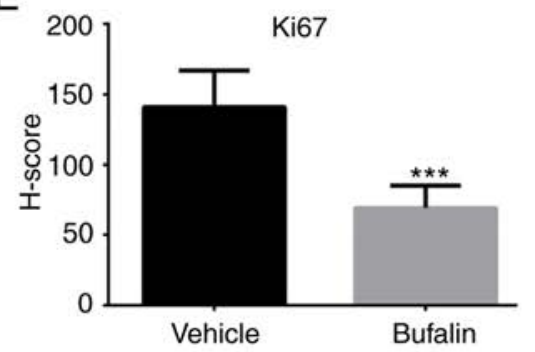

F

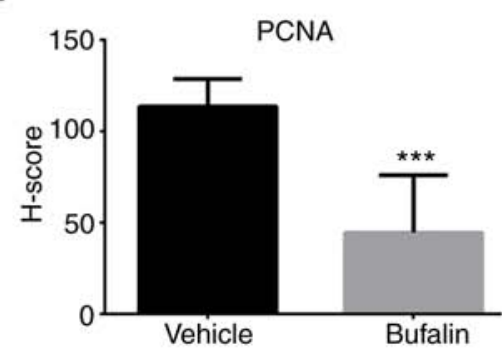

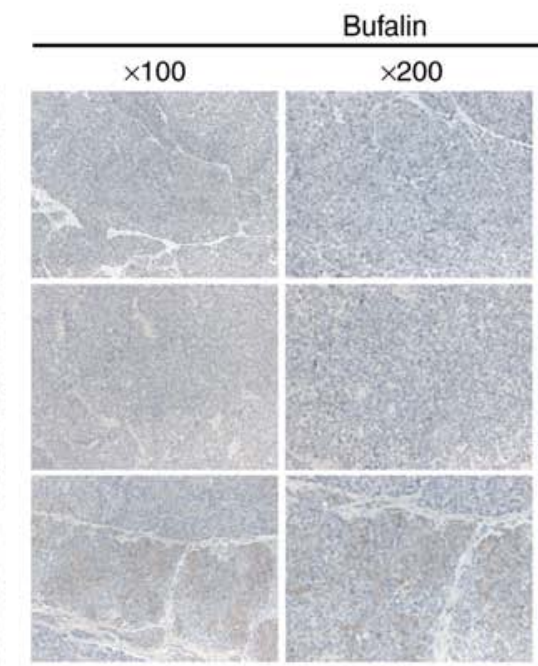

G

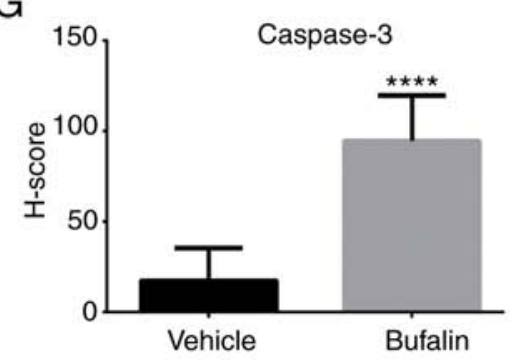

Figure 6. Bufalin inhibits tumor growth in vivo. (A) Image of sacrificed nude mice and xenografts. (B) Tumor volume and (C) tumor weight were significantly reduced after bufalin treatment. (D) Ki67, PCNA and caspase-3 expression levels in xenograft tumor tissues were detected via immunohistochemistry (magnifications, x100, x200 and x400). H-scores indicating expression levels of (E) Ki67, (F) PCNA and (G) caspase-3 based on percentage of positively stained cells and staining intensity. Data are presented as the mean $\pm \mathrm{SD}(\mathrm{n}=5) .{ }^{* * *} \mathrm{P}<0.001,{ }^{* * * *} \mathrm{P}<0.0001$ vs. vehicle. H-score, histologic score; PCNA, proliferating cell nuclear antigen.

of the substrate the compound binds to. Therefore, further experiments are required to identify other targets.

To the best of the authors' knowledge, this is the first report demonstrating the effective antitumor effects of bufalin in neuroblastoma in vitro and in vivo. Regardless of MYCN amplification status, bufalin exhibited consistent antitumor activity, indicating that the antitumor activity of bufalin was MYCN-independent. The Children's Oncology Group stratifies the patients into low risk, medium risk and high-risk group based on a number of variables, including age, MYCN status, pathology, DNA polyploid and differentiation status; the status of MYCN is an important factor for assessing clinical malignant behavior, and is strongly associated with poor prognosis, even with intensive chemotherapy regimens $(5,7)$. Indeed, MYCN amplification is an important in patients with high-risk neuroblastoma (46). SK-N-BE(2) is a MYCN amplification human neuroblastoma cell line derived from children with high-risk neuroblastoma $(47,48)$. Thus, the present findings suggested potential novel treatment strategies for patients with high-risk neuroblastoma.

The in vivo experiments in the present study also revealed that low-dose bufalin did not cause nude mouse death, but effectively inhibited tumor growth. However, the physical conditions of the mice, such as organ function, were not assessed in detail. The mice were sacrificed following treatment and there was no possibility of observing sequelae. 
Therefore, to evaluate the clinical viability of bufalin, further experiments are required to assess its safety. There have been a number of studies dedicated to reducing the toxicity of bufalin and improving its efficacy (49-51).

In conclusion, the present study demonstrated that the antitumor effects of bufalin in neuroblastoma in vitro occurred via targeting of the ETC. ETC disruption-induced ROS accumulation reduced the $\Delta \Psi \mathrm{m}$ and increased the permeability of the mitochondrial membrane, causing accumulation of cytochrome $c$ in the cytoplasm. As a result, cytochrome $c$ may activate the downstream caspase-3 cascade, inducing apoptosis; however, further studies are required to validate these proposed molecular mechanisms, and elucidate the potential binding sites of bufalin.

\section{Acknowledgements}

Immunohistochemistry staining was performed by Servicebio, lnc.

\section{Funding}

The present study was supported by the Suzhou Clinical Medicine Innovation Team Introduction Project (grant no. SZYJTD201706 to YW) and the Natural Science Foundation of China (grant no. 81874234 to ZW).

\section{Availability of data and materials}

The datasets generated and/or analyzed during the current study are available from the corresponding author on reasonable request.

\section{Authors' contributions}

LP, LN, SY and AB performed experiments. YY and YW designed the study. ZT and ZW analyzed and interpreted data, and managed the project. All authors read and approved the final manuscript.

\section{Ethics approval and consent to participate}

Ethical approval for animal experiments was obtained from the Ethics Committee of Xinhua Hospital (approval no. XHEC-F-2020-011).

\section{Patient consent for publication}

Not applicable.

\section{Competing interests}

The authors declare that they have no competing interests.

\section{References}

1. Maris JM, Hogarty MD, Bagatell R and Cohn SL: Neuroblastoma. Lancet 369: 2106-2120, 2007.

2. Brodeur GM: Neuroblastoma: Biological insights into a clinical enigma. Nat Rev Cancer 3: 203-216, 2003.
3. Ackermann S, Cartolano M, Hero B, Welte A, Kahlert Y, Roderwieser A, Bartenhagen C, Walter E, Gecht J, Kerschke L, et al: A mechanistic classification of clinical phenotypes in neuroblastoma. Science 362: 1165-1170, 2018.

4. Matthay KK, Maris JM, Schleiermacher G, Nakagawara A, Mackall CL, Diller L and Weiss WA: Neuroblastoma. Nat Rev Dis Primers 2: 16078, 2016.

5. Whittle SB, Smith V, Doherty E, Zhao S, McCarty S and Zage PE: Overview and recent advances in the treatment of neuroblastoma. Expert Rev Anticancer Ther 17: 369-386, 2017.

6. Cheung NK and Dyer MA: Neuroblastoma: Developmental biology, cancer genomics and immunotherapy. Nat Rev Cancer 13: 397-411, 2013.

7. Morgenstern DA, Bagatell R, Cohn SL, Hogarty MD, Maris JM, Moreno L, Park JR, Pearson AD, Schleiermacher G, Valteau-Couanet $\mathrm{D}$, et al: The challenge of defining 'ultra-high-risk' neuroblastoma. Pediatr Blood Cancer 66: e27556, 2019.

8. Ma Z, Fan Y, Wu Y, Kebebe D, Zhang B, Lu P, Pi J and Liu Z: Traditional Chinese medicine-combination therapies utilizing nanotechnology-based targeted delivery systems: A new strategy for antitumor treatment. Int J Nanomedicine 14: 2029-2053, 2019.

9. Zhang Y, Dong Y, Melkus MW, Yin S, Tang SN, Jiang P, Pramanik K, Wu W, Kim S, Ye M, et al: Role of P53-Senescence induction in suppression of LNCaP prostate cancer growth by cardiotonic compound bufalin. Mol Cancer Ther 17: 2341-2352, 2018.

10. Wu SH, Hsiao YT, Chen JC, Lin JH, Hsu SC, Hsia TC, Yang ST, Hsu WH and Chung JG: Bufalin alters gene expressions associated DNA damage, cell cycle, and apoptosis in human lung cancer NCI-H460 cells in vitro. Molecules 19: 6047-6057, 2014.

11. Hu F, Han J, Zhai B, Ming X, Zhuang L, Liu Y, Pan S and Liu T: Blocking autophagy enhances the apoptosis effect of bufalin on human hepatocellular carcinoma cells through endoplasmic reticulum stress and JNK activation. Apoptosis 19: 210-223, 2014.

12. Yeh JY, Huang WJ, Kan SF and Wang PS: Effects of bufalin and cinobufagin on the proliferation of androgen dependent and independent prostate cancer cells. Prostate 54: 112-124, 2003.

13. Li Y, Tian X, Liu X and Gong P: Bufalin inhibits human breast cancer tumorigenesis by inducing cell death through the ROS-mediated RIP1/RIP3/PARP-1 pathways. Carcinogenesis 39: 700-707, 2018

14. Liu X, Xiao XY, Shou QY, Yan JF, Chen L, Fu HY and Wang JC: Bufalin inhibits pancreatic cancer by inducing cell cycle arrest via the $\mathrm{c}-\mathrm{Myc} / \mathrm{NF}-\mathrm{kB}$ pathway. J Ethnopharmacol 193: 538-545, 2016.

15. Liu T, Wu C, Weng G, Zhao Z, He X, Fu C, Sui Z and Huang SX: Bufalin inhibits cellular proliferation and cancer stem cell-like phenotypes via upregulation of MiR-203 in glioma. Cell Physiol Biochem 44: 671-681, 2017.

16. Wu SH, Wu TY, Hsiao YT, Lin JH, Hsu SC, Hsia TC, Yang ST, Hsu WH and Chung JG: Bufalin induces cell death in human lung cancer cells through disruption of DNA damage response pathways. Am J Chin Med 42: 729-742, 2014.

17. Zhu Z, Sun H, Ma G, Wang Z, Li E, Liu Y and Liu Y: Bufalin induces lung cancer cell apoptosis via the inhibition of PI3K/Akt pathway. Int J Mol Sci 13: 2025-2035, 2012.

18. Lan YL, Wang X, Lou JC, Xing JS, Yu ZL, Wang H, Zou S, Ma $X$ and Zhang B: Bufalin inhibits glioblastoma growth by promoting proteasomal degradation of the $\mathrm{Na}^{+} / \mathrm{K}^{+}$-ATPase $\alpha 1$ subunit. Biomed Pharmacother 103: 204-215, 2018.

19. Cox J and Mann M: MaxQuant enables high peptide identification rates, individualized p.p.b.-range mass accuracies and proteome-wide protein quantification. Nat Biotechnol 26: 1367-1372, 2008.

20. Cox J, Neuhauser N, Michalski A, Scheltema RA, Olsen JV and Mann M: Andromeda: A peptide search engine integrated into the MaxQuant environment. J Proteome Res 10: 1794-1805, 2011.

21. Ashburner M, Ball CA, Blake JA, Botstein D, Butler H, Cherry JM, Davis AP, Dolinski K, Dwight SS, Eppig JT, et al: Gene ontology: Tool for the unification of biology. The gene ontology consortium. Nat Genet 25: 25-29, 2000.

22. The Gene Ontology Consortium: The gene ontology resource: 20 years and still GOing strong. Nucleic Acids Res 47: D330-D338, 2019.

23. Yeo W, Chan SL, Mo FK, Chu CM, Hui JW, Tong JH, Chan AW, Koh J, Hui EP, Loong H, et al: Phase I/II study of temsirolimus for patients with unresectable hepatocellular carcinoma (HCC)-a correlative study to explore potential biomarkers for response. BMC Cancer 15: 395, 2015. 
24. Qi F, Li A, Inagaki Y, Kokudo N, Tamura S, Nakata M and Tang W: Antitumor activity of extracts and compounds from the skin of the toad Bufo bufo gargarizans cantor. Int Immunopharmacol 11: 342-349, 2011

25. Jackson PA, Widen JC, Harki DA and Brummond KM: Covalent modifiers: A chemical perspective on the reactivity of $\alpha, \beta$-Unsaturated carbonyls with thiols via hetero-michae addition reactions. J Med Chem 60: 839-885, 2017.

26. Wang Y, Lonard DM, Yu Y, Chow DC, Palzkill TG, Wang J, Qi R, Matzuk AJ, Song X, Madoux F, et al: Bufalin is a potent small-molecule inhibitor of the steroid receptor coactivators SRC-3 and SRC-1. Cancer Res 74: 1506-1517, 2014.

27. Larosa V and Remacle C: Insights into the respiratory chain and oxidative stress. Biosci Rep 38: BSR20171492, 2018.

28. Battogtokh G, Choi YS, Kang DS, Park SJ, Shim MS, Huh KM, Cho YY, Lee JY, Lee HS and Kang HC: Mitochondria-targeting drug conjugates for cytotoxic, anti-oxidizing and sensing purposes: Current strategies and future perspectives. Acta Pharm Sin B 8: 862-880, 2018.

29. Hou XS, Wang HS, Mugaka BP, Yang GJ and Ding Y: Mitochondria: Promising organelle targets for cancer diagnosis and treatment. Biomater Sci 6: 2786-2797, 2018.

30. Dai G, Zheng D, Guo W, Yang J and Cheng AY: Cinobufagin induces apoptosis in osteosarcoma cells via the mitochondria-mediated apoptotic pathway. Cell Physiol Biochem 46: 1134-1147, 2018.

31. Li P, Nijhawan D, Budihardjo I, Srinivasula SM, Ahmad M, Alnemri ES and Wang X: Cytochrome $c$ and dATP-dependent formation of Apaf-1/caspase-9 complex initiates an apoptotic protease cascade. Cell 91: 479-489, 1997.

32. Yu Z, Feng H, Sun X, Zhuo Y, Li M, Zhou Z, Huang L, Jiang Y, Zhu X, Zhang X, et al: Bufalin suppresses hepatocarcinogenesis by targeting $\beta$-catenin/TCF signaling via cell cycle-related kinase. Sci Rep 8: 3891, 2018.

33. Liu J, Zhang Y, Sun S, Zhang G, Jiang K, Sun P, Zhang Y, Yao B, Sui R, Chen Y, et al: Bufalin induces apoptosis and improves the sensitivity of human glioma stem-like cells to temozolamide. Oncol Res 27: 475-486, 2019.

34. Li H, Hu S, Pang Y, Li M, Chen L, Liu F, Liu M, Wang Z and Cheng $X$ : Bufalin inhibits glycolysis-induced cell growth and proliferation through the suppression of Integrin $\beta 2 /$ FAK signaling pathway in ovarian cancer. Am J Cancer Res 8: 1288-1296, 2018.

35. Zhang L, Nakaya K, Yoshida T and Kuroiwa Y: Induction by bufalin of differentiation of human leukemia cells HL60, U937, and ML1 toward macrophage/monocyte-like cells and its potent synergistic effect on the differentiation of human leukemia cells in combination with other inducers. Cancer Res 52: 4634-4641, 1992.

36. Xie CM, Chan WY, Yu S, Zhao J and Cheng CH: Bufalin induces autophagy-mediated cell death in human colon cancer cells through reactive oxygen species generation and JNK activation. Free Radic Biol Med 51: 1365-1375, 2011.

37. Su EY, Chu YL, Chueh FS, Ma YS, Peng SF, Huang WW, Liao CL, Huang AC and Chung JG: Bufalin induces apoptotic cell death in human nasopharyngeal carcinoma cells through mitochondrial ROS and TRAIL pathways. Am J Chin Med 47: 237-257, 2019
38. Liu T, Jia T, Yuan X, Liu C, Sun J, Ni Z, Xu J, Wang X and Yuan Y: Development of octreotide-conjugated polymeric prodrug of bufalin for targeted delivery to somatostatin receptor 2 overexpressing breast cancer in vitro and in vivo. Int J Nanomedicine 11: 2235-2250, 2016.

39. Xu J, Sun Y, Yuan Z, Bao Y, Li R, Liu C, Qiu Y, Xu K, Shi X, Yu H, et al: Bufalin-loaded CaP/DPPE-PEG-EGF nanospheres: Preparation, cellular uptake, distribution, and anti-tumor effects. J Biomed Nanotechnol 15: 329-339, 2019.

40. Shen S, Zhang Y, Wang Z, Liu R and Gong X: Bufalin induces the interplay between apoptosis and autophagy in glioma cells through endoplasmic reticulum stress. Int J Biol Sci 10: 212-224, 2014.

41. Xiang RF, Wang Y, Zhang N, Xu WB, Cao Y, Tong J, Li JM, Wu YL and Yan H: MK2206 enhances the cytocidal effects of bufalin in multiple myeloma by inhibiting the AKT/mTOR pathway. Cell Death Dis 8: e2776, 2017.

42. Zhang X, Huang Q, Wang X, Xu Y, Xu R, Han M, Huang B, Chen A, Qiu C, Sun T, et al: Bufalin enhances radiosensitivity of glioblastoma by suppressing mitochondrial function and DNA damage repair. Biomed Pharmacother 94: 627-635, 2017.

43. Drewes G and Knapp S: Chemoproteomics and chemical probes for target discovery. Trends Biotechnol 36: 1275-1286, 2018.

44. Klaeger S, Heinzlmeir S, Wilhelm M, Polzer H, Vick B, Koenig PA, Reinecke M, Ruprecht B, Petzoldt S, Meng C, et al: The target landscape of clinical kinase drugs. Science 358: eaan4368, 2017.

45. Bantscheff M, Eberhard D, Abraham Y, Bastuck S, Boesche M, Hobson S, Mathieson T, Perrin J, Raida M, Rau C, et al: Quantitative chemical proteomics reveals mechanisms of action of clinical ABL kinase inhibitors. Nat Biotechnol 25: 1035-1044, 2007.

46. Seeger RC, Brodeur GM, Sather H, Dalton A, Siegel SE, Wong KY and Hammond D: Association of multiple copies of the $\mathrm{N}$-myc oncogene with rapid progression of neuroblastomas. N Engl J Med 313: 1111-1116, 1985.

47. Biedler JL and Spengler BA: Metaphase chromosome anomaly: Association with drug resistance and cell-specific products Science 191: 185-187, 1976

48. Biedler JL, Roffler-Tarlov S, Schachner M and Freedman LS: Multiple neurotransmitter synthesis by human neuroblastoma cell lines and clones. Cancer Res 38: 3751-3757, 1978.

49. Liu T, Yuan X, Jia T, Liu C, Ni Z, Qin Z and Yuan Y: Polymeric prodrug of bufalin for increasing solubility and stability: Synthesis and anticancer study in vitro and in vivo. Int J Pharm 506: 382-393, 2016.

50. Chen Q and Liu J: Transferrin and folic acid co-modified bufalin-loaded nanoliposomes: Preparation, characterization, and application in anticancer activity. Int J Nanomedicine 13: 6009-6018, 2018

51. Shi XJ, Qiu YY, Yu H, Liu C, Yuan YX, Yin PH and Liu T: Increasing the anticancer performance of bufalin (BUF) by introducing an endosome-escaping polymer and tumor-targeting peptide in the design of a polymeric prodrug. Colloids Surf B Biointerfaces 166: 224-234, 2018.

This work is licensed under a Creative Commons Attribution-NonCommercial-NoDerivatives 4.0 International (CC BY-NC-ND 4.0) License. 